\title{
Capillary pressure and relative permeability correlations for transition zones of carbonate reservoirs
}

\author{
Shuaishuai Shi $^{1} \cdot$ Hadi Belhaj $^{1} \cdot$ Achinta Bera $^{1}[$
}

Received: 26 March 2017/Accepted: 13 August 2017/Published online: 20 August 2017

(C) The Author(s) 2017. This article is an open access publication

\begin{abstract}
A sizable oil reserves are held in a thick oil/ water capillary transition zones in the carbonate reservoirs, but it is an ongoing challenge to accurately describe the relationship between capillary pressure, relative permeability and oil/water saturation due to the complex wettability variation, pore geometry and heterogeneity throughout the reservoir column. It has been shown that a proper interpretation of relative permeability and capillary pressure including hysteresis has a substantial influence on the prediction and optimization of field production, especially for a heterogeneous carbonate reservoir with a thick transition zone. The conventional models, such as Corey method and Leverett J-function, cannot precisely present the behaviors of capillary pressure and relative permeability of transition zones in carbonate reservoirs. In the present work, a study has been conducted to provide an improved understanding of capillary pressure and relative permeability of the transition zones in carbonate reservoirs by implementing and optimizing recently developed models considering mixed-wet property and geological heterogeneity. For single core plug and each reservoir rock typing classified on the basis of petrophysical properties, the applicability to generate bounding drainage and imbibition curves of the models was tested with fitting parameters by comparing with experimental data. Also, a comprehensive assessment was provided about the feasibility and efficiency of the models along with an evaluation of the hysteresis between bounding drainage and
\end{abstract}

Achinta Bera

achintachm@gmail.com

1 Petroleum Engineering Department, The Petroleum Institute, Sas Al Nakhl Campus, Khalifa University of Science and Technology, P.O. Box 2533, Abu Dhabi, UAE imbibition curves. The results showed excellent matches in the case of Masalmeh model (SPE Reserv Eval Eng 10(02):191-204, 2007) with a correlation coefficient value of 0.95 , in which mixed-wet and pore size distribution are taken into account. Therefore, it can be stated that the work conducted in this study could be used as a guide for further investigation and understanding of transition zones in carbonate reservoirs.

Keywords Transition zones - Carbonate reservoirs · Capillary pressure hysteresis - Relative permeability . Reservoir simulation

\section{Introduction}

The capillary transition zone is referred to a reservoir interval from the oil-water contact (OWC) up straight to the height where water saturation reaches its irreducible condition, Swir (Bera and Belhaj 2016; Masalmeh et al. 2007; Nono et al. 2014). The thickness of a capillary transition zone may vary from a few feet in high-permeability reservoirs to more than 300 feet in low-permeability reservoirs such as carbonate reservoirs, due to its extreme heterogeneity. Transition zone in the reservoir may hold a substantial portion of oil reserves in place. The petroleum reserves and oil recovery depend heavily on several geological and petrophysical properties based on special core analysis (SCAL) such as capillary pressure and relative permeability as a function of saturation (Spearing et al. 2014; Mohamed et al. 2017). It is crucial to express the relationship between capillary pressure and relative permeability and saturation to obtain typical capillary pressure and relative permeability curves for reservoir modeling and simulation. For water-wet reservoirs, a number of models 
have been proposed to correlate capillary pressure and relative permeability with water saturation (Masalmeh et al. 2007; Nono et al. 2014; Carlson 1981; Skjaeveland et al. 2000; Kjosavik et al. 2002). However, it is difficult to precisely correlate the capillary pressure and relative permeability in the transition zones of carbonate reservoirs due to its high degree of heterogeneity and complex properties of wettability. Capillary transition zones in carbonate reservoirs have a variety of wettability states, whereas it is more water wet at the OWC where initial oil saturation $\left(S_{\mathrm{oi}}\right)$ equals to residual oil saturation up vertically to oil wet at the irreducible water saturation level. This type of wettability should be considered for more realistic modeling of reservoir situation. A schematic diagram to depict the capillary pressure and permeability behaviors in the transition zone is shown in Fig. 1.

Leverett J-function (Leverett 1941) is widely used as drainage-type capillary pressure model, but it is restricted to water-wet reservoirs and may generate erroneous results to describe mix-wet reservoirs (Masalmeh 2002). Thomeer (1960) introduced a pore geometrical factor in his model to comprise the heterogeneity properties of the porous medium. Clerke and Martin (2004) determined the water saturation in transition zones of carbonate reservoirs on the basis of Thomeer model. However, Thomeer method is not suitable for mixed-wet porous system and cannot match well with experimental results. Most of the models for capillary pressure correlation have been developed with two adjustable parameters. One parameter indicates the pore size distribution considering the curvature of capillary pressure curve, and other one specifies the mean of entry capillary pressure, i.e., the actual level of the capillary pressure. Brooks and Corey (1966) proposed a capillary pressure correlation method comprising two fitting parameters to represent the pore size distribution and entry capillary pressure, but this model is limited to water-wet reservoirs. The previously developed models are restricted to first drainage and spontaneous imbibition capillary pressure. Huang et al. (1997) extended the capillary pressure correlation between forced imbibition and forced secondary drainage capillary pressure by using the same expression of first drainage capillary pressure.

Land (1968) initialized and defined the concept of hysteresis to describe the trapping and explained its effect on relative permeability. Ever since, all the models are developed on the basis of his idea to represent hysteresis. Killough (1976) and Carlson (1981) models are formalized as industry standards, and they both focused on the nonwetting phase hysteresis in a two-phase system porous medium with neglecting the trapping of wetting phase. As a matter of fact, all these models were developed without considering the wettability variation like in the transition zones of carbonate reservoirs. Skjaeveland et al. (2000) introduced oil-wet branch referring from Brooks and Corey method of water-wet branch equation and extended it to the mixed-wet reservoir for capillary pressure correlation. Later Kjosavik et al. (2002) obtained the relative permeability correlation method for mixed-wet reservoirs by the weighting of capillary pressure. To improve all the existing models and their better applicability in the transition zones of carbonate reservoirs, Masalmeh et al. (2007) introduced a term on the basis of Kjosavik method to describe different shapes of capillary pressure curves, especially for the cases of dual porosity systems.

It is widely accepted that most of the reservoirs are mixed-wet like carbonate reservoirs, especially for the transition zones where wettability varies through the whole interval (Laroche et al. 1999). In order to implement the
Fig. 1 Schematic diagram of transition zone description in carbonate reservoir with behaviors of capillary pressure and relative permeability

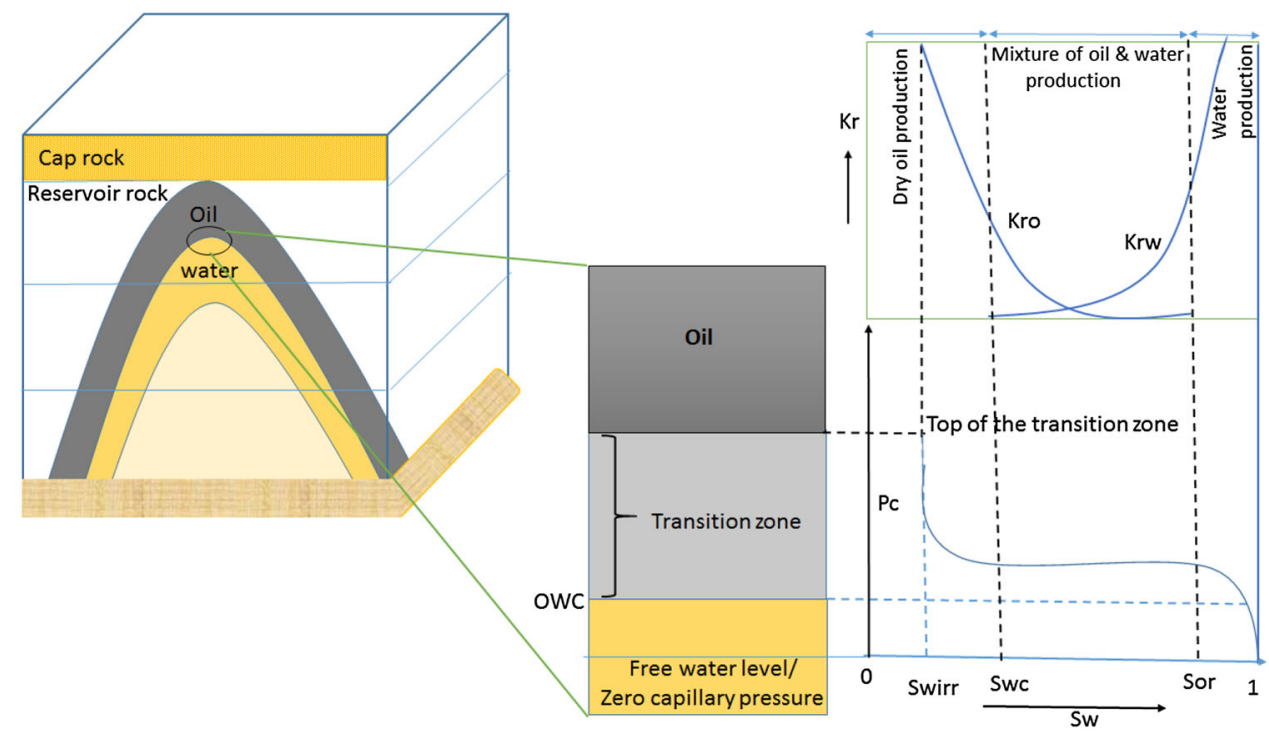


Table 1 Plug core samples properties

\begin{tabular}{lllllll}
\hline $\begin{array}{l}\text { Sample plug } \\
\text { number }\end{array}$ & $\begin{array}{l}\text { Depth } \\
(\mathrm{ft})\end{array}$ & $\begin{array}{l}\text { Zones in oil } \\
\text { column }\end{array}$ & $\begin{array}{l}\text { Permeability, } \\
k(\mathrm{mD})\end{array}$ & $\begin{array}{l}\text { Porosity, } \Phi \\
(\%)\end{array}$ & $\begin{array}{l}\text { Connate water saturation, } \\
S_{\mathrm{wc}}\end{array}$ & $\begin{array}{l}\text { Residual oil saturation, } \\
S_{\text {or }}\end{array}$ \\
\hline 1 & 9511.16 & Upper zone & 12.66 & 19.9 & 0.19 & 0.11 \\
$1-4$ & 9511.66 & & 4.60 & 16.4 & 0.12 & 0.17 \\
$1-5$ & 9514.17 & & 1.50 & 21.1 & 0.10 & 0.11 \\
$1-25$ & 9577.17 & Middle zone & 0.46 & 14.2 & 0.28 & 0.08 \\
$1-26$ & 9580.17 & & 1.70 & 18.1 & 0.40 & 0.17 \\
8 & 9580.83 & & 7.84 & 15.4 & 0.16 & 0.23 \\
\hline
\end{tabular}

properties of mixed wet into reservoir modeling and simulation, sound representatives and validated capillary pressure and relative permeability correlations are required in the study of transition zones of carbonate reservoirs. Therefore, correlations of relative permeability and capillary pressure have been presented to understand the dynamic behaviors of transition zones of carbonate reservoirs in the present work. The correlations of capillary pressure and relative permeability have been studied based on Skjaeveland and Masalmeh models, respectively. The current approach of the work would be able to provide helpful information on capillary pressure and relative permeability correlations which are very important for transition zones of carbonate reservoirs.

\section{Capillary pressure correlation}

Capillary pressure correlation in the modeling of fluid flow behavior in transition zones of carbonate reservoirs is very crucial to understand the impact of wettability variation on reservoir dynamics. Proper correlation of capillary pressure is required to demonstrate the transition zone behavior in different wettability states of the reservoir. Skjaeveland et al. (2000) developed a general capillary pressure $\left(P_{\mathrm{c}}\right)$ correlation for the mixed-wet reservoir as shown in the following Eq. 1:

$P_{\mathrm{c}}=\frac{c_{\mathrm{w}}}{\left(\frac{S_{\mathrm{w}}-S_{\mathrm{wc}}}{1-S_{\mathrm{wc}}}\right)^{a_{\mathrm{w}}}}+\frac{c_{\mathrm{o}}}{\left(\frac{S_{\mathrm{o}}-S_{\mathrm{or}}}{1-S_{\mathrm{or}}}\right)^{a_{\mathrm{o}}}}$

where $\mathrm{c}$ is the entry capillary pressure, and $1 / a$ is the pore size distribution index, $S_{\mathrm{wc}}$ is the connate water saturation and $S_{\text {or }}$ represents the residual oil saturation. The terms, $a$ 's and $c$ 's, are constants, and they can be used as one set for imbibition and the other for drainage process. An imbibition curve is modeled by four constants $\left(a_{\mathrm{wi}}, a_{\mathrm{oi}}, c_{\mathrm{wi}}, c_{\mathrm{oi}}\right)$, and a secondary drainage curve from $S_{\mathrm{or}}$ to $S_{\mathrm{wc}}$ by the constants $\left(a_{\mathrm{wd}}, a_{\mathrm{od}}, c_{\mathrm{wd}}, c_{\mathrm{od}}\right)$. The constraints on the constants, $a_{\mathrm{w}}, a_{\mathrm{o}}$ and $c_{\mathrm{w}}$, are positive numbers and $\mathrm{c}_{\mathrm{o}}$ is a negative number.
In order to validate the applicability of this model by Skjaeveland, we compared the results against laboratory experimental data obtained from SCAL. Six core samples (three samples from the upper zone and the other three from the middle zone) are taken from the transition zone of a carbonate reservoir in Abu Dhabi region to process the validation of capillary pressure correlation. The sample plug properties of permeability, porosity, connate water saturation and residual oil saturation are shown in Table 1 . Curve fitting tool of MATLAB was used to conduct the matching between model results and experimental ones, and an example of the user interface is shown in Fig. 2. The values of fitting parameters are obtained by curve fitting as well as the correlation coefficients for both imbibition and secondary drainage are shown in Tables 2 and 3 . The calculated fitting parameters imbibition and secondary drainage do not show any consistency value. This fact may be explained by the local heterogeneity of the reservoir. With increasing depth, the values of the fitting parameters in imbibition do not follow any trend. The same fact also occurs in secondary drainage. Based on the irregular tend in calculated fitting parameters for capillary pressure in transition zones of carbonate reservoirs, it can be stated that the water-oil movement and their behaviors are really complex in nature. Therefore, proper understanding and incorporation of specific terms in correlation that can signify the complex behaviors of oil and water in transition zone are utmost important for predicting the nature of capillary pressure curves for modeling and simulation. Also, the dynamics of transition zone is dominated by relationship between the capillary pressure and saturation. As a result, a complete picture of capillary pressure behavior in the entire saturation zone is required for the same purpose of the dynamic modeling of capillary transition zones.

By applying the Skjaeveland method, both imbibition and secondary drainage processes of six core samples are investigated, respectively, and compared with experimental results. According to Figs. 3, 4, 5, 6, 7 and 8, the matches between model and experimental results are excellently 


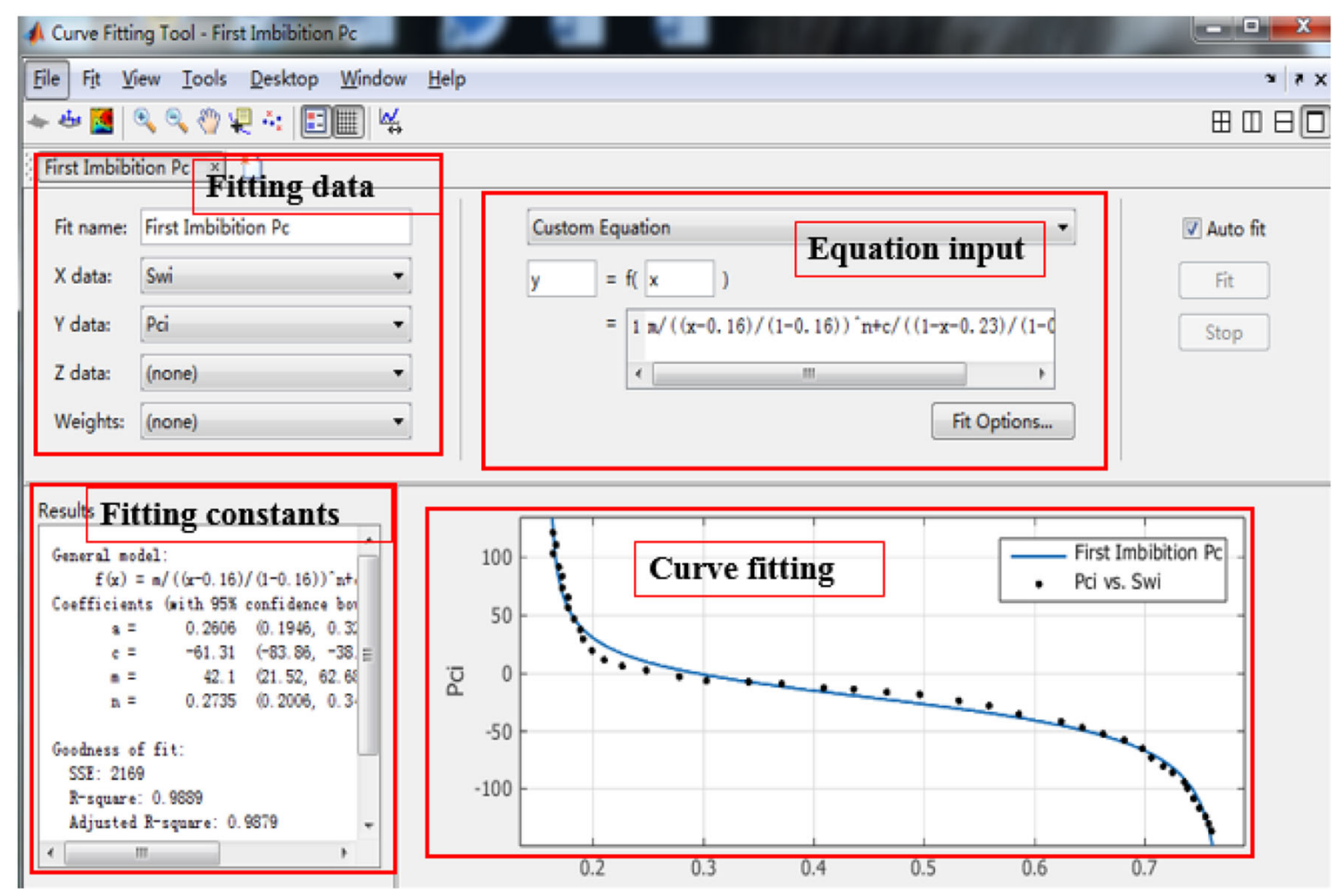

Fig. 2 MATLAB user interface example of imbibition $P_{\mathrm{c}}$ curve fitting for core plug \#8

Table 2 Results of fitting constants for imbibition

\begin{tabular}{|c|c|c|c|c|c|}
\hline Sample plug & $a_{\mathrm{wi}}$ & $a_{\mathrm{oi}}$ & $c_{\mathrm{wi}}$ & $c_{\mathrm{oi}}$ & $R^{2}$ \\
\hline 1 & 0.2929 & 0.3813 & 23.06 & -27.52 & 0.9778 \\
\hline $1-4$ & 0.3306 & 0.2980 & 26.11 & -48.67 & 0.9886 \\
\hline $1-5$ & 0.1334 & 0.1073 & 145.8 & -179.1 & 0.9943 \\
\hline $1-25$ & 0.7081 & 0.3669 & 6.5 & -30.45 & 0.9662 \\
\hline $1-26$ & 0.8471 & 0.5173 & 3.55 & -16.61 & 0.9855 \\
\hline 8 & 0.2735 & 0.2606 & 42.1 & -61.31 & 0.9889 \\
\hline
\end{tabular}

Table 3 Results of fitting constants for secondary drainage

\begin{tabular}{|c|c|c|c|c|c|}
\hline Sample plug & $a_{\mathrm{wd}}$ & $a_{\mathrm{od}}$ & $c_{\mathrm{wd}}$ & $c_{\mathrm{od}}$ & $R^{2}$ \\
\hline 1 & 0.6078 & 0.4583 & 10.4 & -9.247 & 0.9881 \\
\hline $1-4$ & 0.3129 & 0.1849 & 44.69 & -47.51 & 0.9914 \\
\hline $1-5$ & 0.2408 & 0.2167 & 64.1 & -62.54 & 0.9966 \\
\hline $1-25$ & 0.1512 & 0.063 & 177.1 & -177.6 & 0.9530 \\
\hline $1-26$ & 0.4100 & 0.2161 & 37.17 & -38.49 & 0.9640 \\
\hline 8 & 0.1039 & 0.07324 & 219.5 & -211.8 & 0.9893 \\
\hline
\end{tabular}

matched with a correlation coefficient above 0.95 regardless of the wettability variation through the interval of the transition zone as shown in Tables 2 and 3. It is also important to mention here that the values of correlation coefficients do not follow any increasing or decreasing trends with depth. This is also an indication of local heterogeneity and variation of wettability of the reservoir rocks. In some of the cases, correlation coefficients are 
Fig. 3 Curve fitting of bounding imbibition and secondary drainage $P_{\mathrm{c}}$ for core plug \#1

Fig. 4 Curve fitting of bounding imbibition and secondary drainage $P_{\mathrm{c}}$ for core plug \#1-4
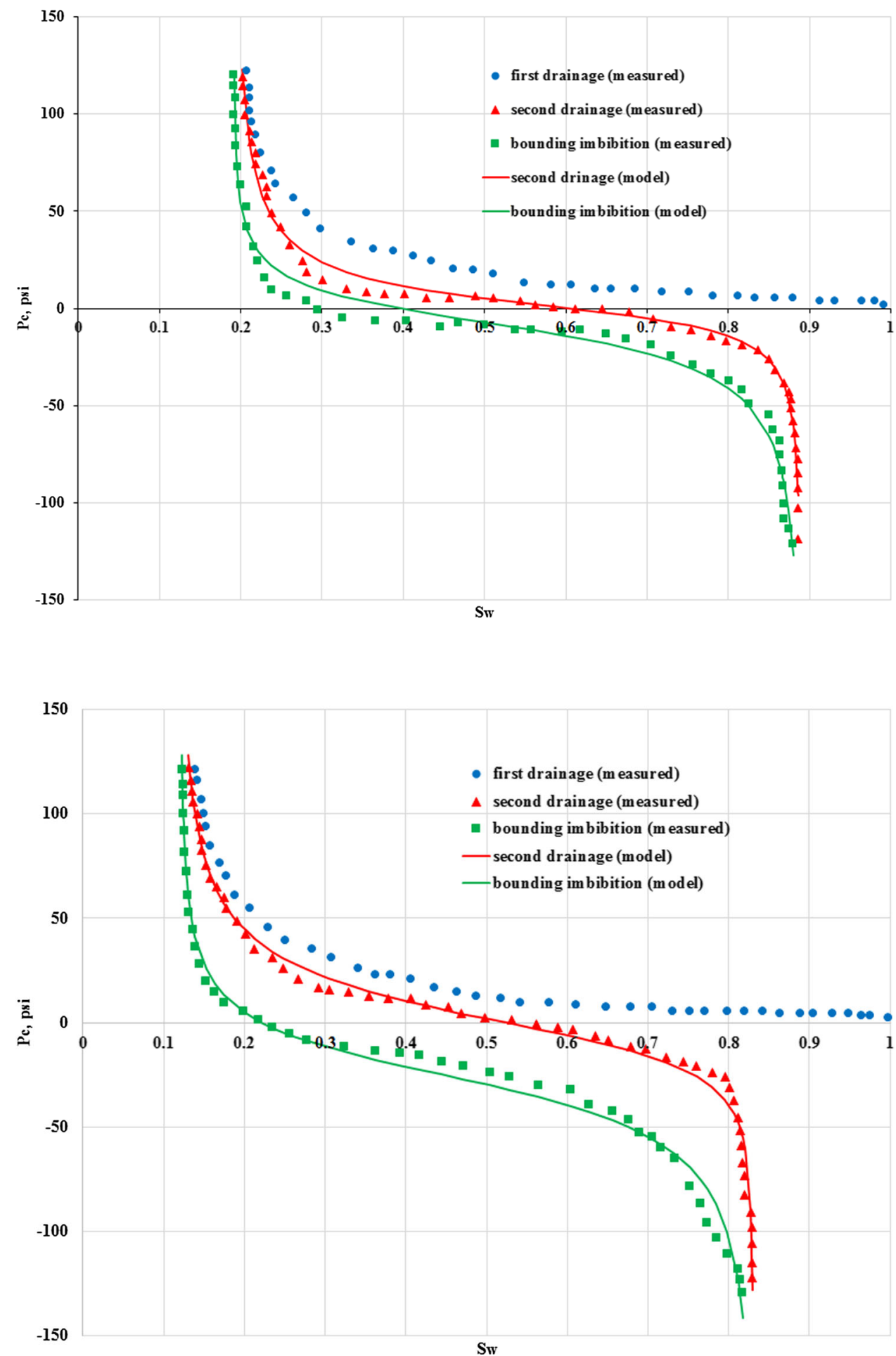

greater than 0.99 demonstrating the better matching between model and experimental data. From the comparison, we found that Skjaeveland method is robust to be applicable for capillary pressure correlation in transition zones of carbonate reservoirs with a change of wettability. This model can be applied to generate representative imbibition and drainage capillary pressure for reservoir modeling and simulation. Besides, this model can be used to describe the capillary pressure of flow path with mix-wet properties for numerical simulation.

In the drainage process, the non-wetting phase displaces wetting phase from the large pores. Therefore, after the process some non-wetting phases remain trapped in the smaller pores causing capillary retention that can explain 
Fig. 5 Curve fitting of bounding imbibition and secondary drainage $P_{\mathrm{c}}$ for core plug \#1-5

Fig. 6 Curve fitting of bounding imbibition and secondary drainage $P_{\mathrm{c}}$ for core plug \#1-25
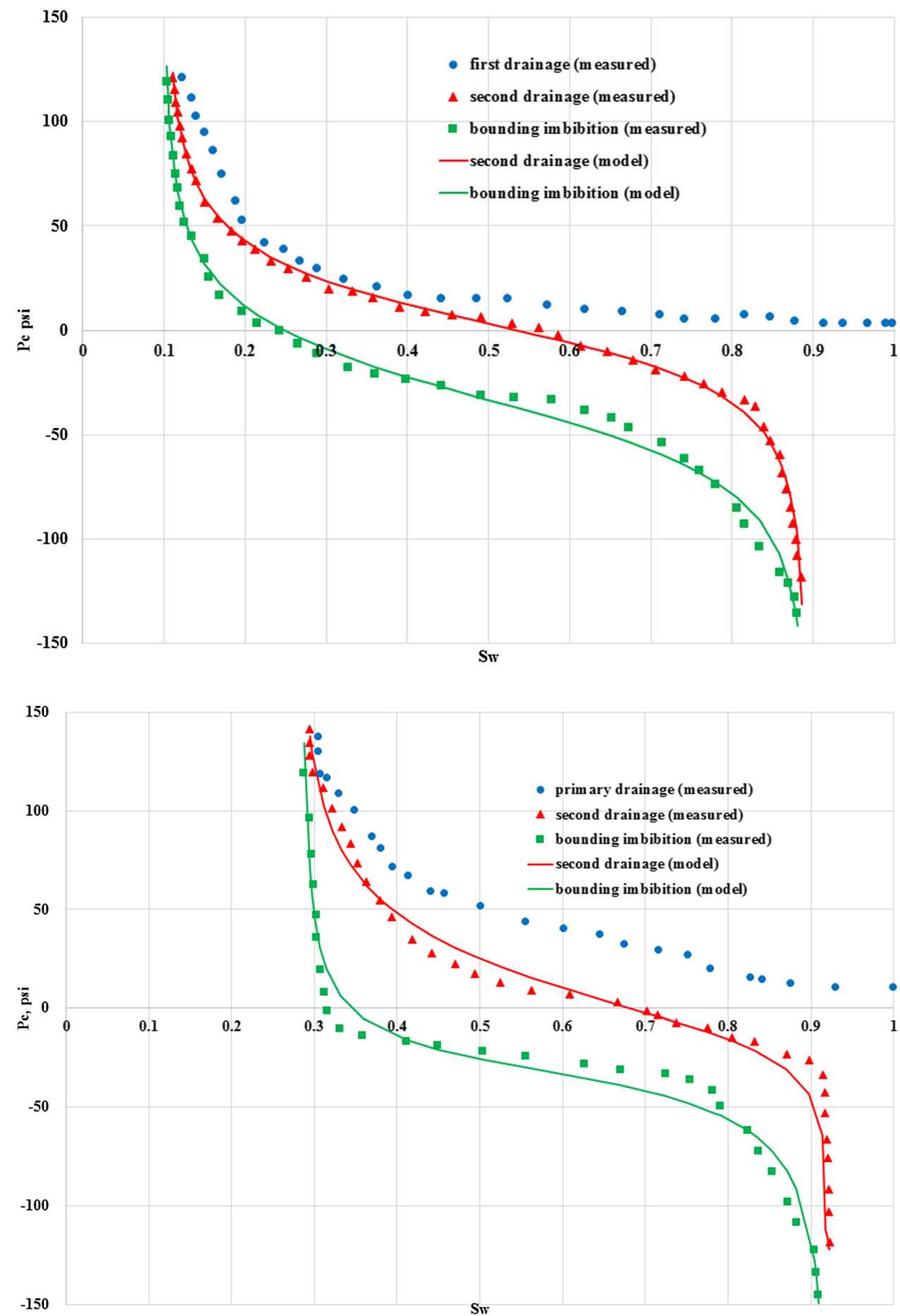

the behavior of drainage curve of capillary pressure at higher saturation than the imbibition one. Imbibition process takes places by displacement of non-wetting phase by wetting phase. In this process, non-wetting phase fluid in smaller pores first gets displaced by wetting phase fluid. As a matter of fact, the imbibition curve shows a high threshold capillary pressure for the same sample up-structure that has low drainage threshold capillary pressure. Due to capillary pressure hysteresis, capillary pressure curves obtained in imbibition process are in the lower range of saturation accordingly.

The nature and shape of primary drainage and imbibition curves for capillary pressure significantly depend on reservoir rock types as well as depth. It is stated that rocks with fine grained and mud-supported rock fabrics have higher capillary pressure than the rock types with coarse 
Fig. 7 Curve fitting of bounding imbibition and secondary drainage $P_{\mathrm{c}}$ for core plug \#1-26

Fig. 8 Curve fitting of bounding imbibition and secondary drainage $P_{\mathrm{c}}$ for core plug \#8
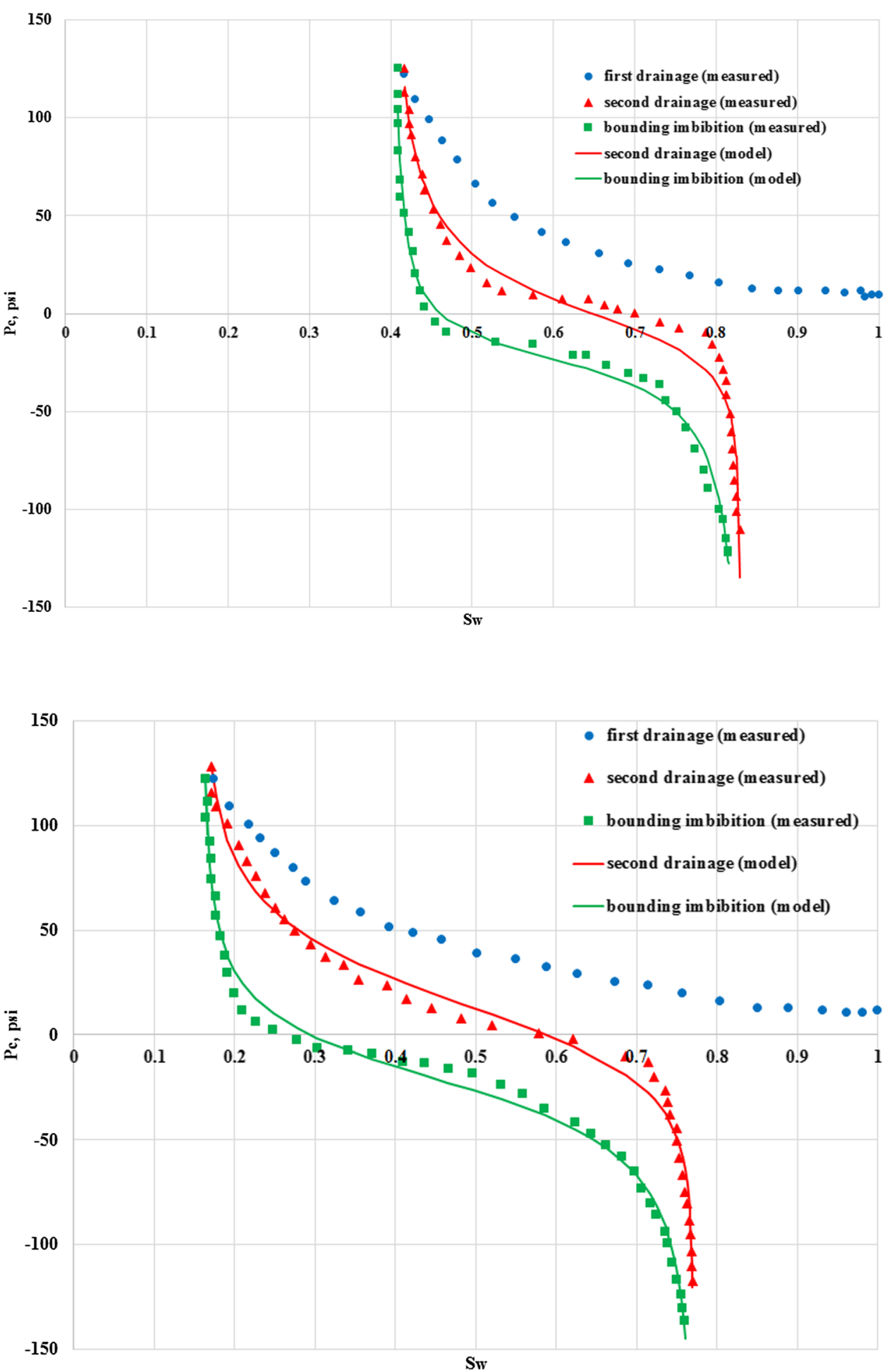

grain at a particular saturation. According to a depth of zone, the shapes of the capillary pressure curves are changed with respect to connate water saturation. Connate water saturation of each zone indicates the wettability of the rock samples. In upper zone, low connate water saturation implies the oil-wet behavior of the rock samples and the middle zone samples with high or medium connate water saturation show intermediate to water-wet behaviors. It is also confirmed that with increasing depth the porosity and permeability of the rock samples are degraded with an increase in connate water saturation. This situation can be explained based on the higher diagenetic overprint toward 

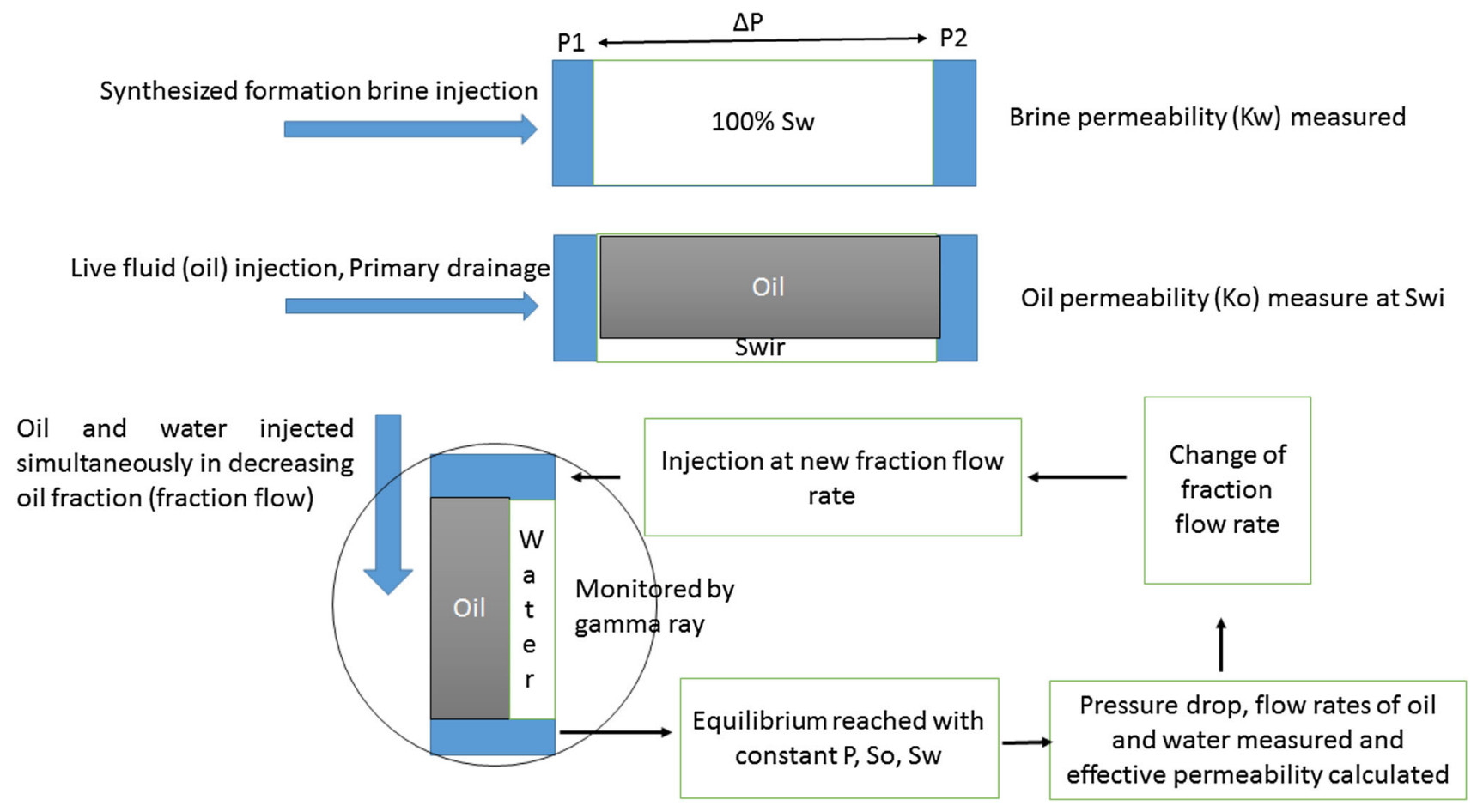

Fig. 9 Schematic diagram of relative permeability measurement procedure by steady state method

the oil water contact along with the high threshold capillary pressure that can ease the formation of thick transition zones in carbonate reservoirs. As we move from Figs. 3, 4, $5,6,7$ and 8 , there is a change in shapes of capillary pressure curves. This is due to change in capillary pressure with depth change of wettability toward water-wet state at the deeper zone. In the transition zone, if we move from top to bottom we will reach to the water-oil contact and then free water level where the capillary pressure is considered to be zero (Fig. 1). As we see from the curves in Figs. 3, 4, $5,6,7$ and 8 , it is possible for the force imbibition capillary curves to become negative as oil saturation approaches residual with increasing water saturation. As a result, the water phase pressure can be higher than that of oil phase at the deeper zone (middle zone), producing a gradient that is steeper than the capillary pressure curves at the less deep zone (upper zone). Therefore, curves in Figs. 6, 7 and 8 are steeper than the curves shown in Figs. 3, 4 and 5.

Accurate evaluation of capillary pressure and relative permeability are very important for investigating hydrocarbon recovery processes. Both of the two parameters are path dependent that is to say that they are different in imbibition and drainage processes, which is generally known as hysteresis effect and makes it difficult to predict. Basic knowledge is required to understand the flow path of wetting and non-wetting phase in reservoirs with displacing and displaced fluids. The terminologies of Morrow (1990) are adopted to represent the capillary pressure curves, drainage indicates a fluid flow of oil displacing water, no matter it is oil wet or water wet, and imbibition indicates a fluid flow of oil displaced by water. Through Figs. 3, 4, 5, 6, 7 and 8, capillary pressure hysteresis can be clearly observed from the secondary drainage and bounding imbibition curves. The hysteresis effects of middle zone core samples are not as pronounced as those from the upper zone. Varying hysteresis is observed due to its dependency on the properties of permeability, porosity and wettability of porous medium. Each rock sample has its typical capillary pressure hysteresis that differs from those of the other ones.

\section{Relative permeability correlation}

Oil-water relative permeability correlations for transition zone carbonate reservoirs are important for reservoir modeling. Several models are available for relative permeability correlation, but they cannot properly demonstrate the variation of wettability of carbonate reservoir (Corey 1954; Land 1971; Killough 1976). Therefore, Masalmeh et al. (2007) proposed a modified Corey model to generate imbibition and drainage $K_{\mathrm{r}}$ curves that match the experimental data. The oil relative permeability is expressed as follows in Eq. 2: 
Table 4 Summary of core plug samples characterization

\begin{tabular}{lcllll}
\hline RRT & Sample plug & Mineral & Grain density (g/cc) & Permeability, $k(\mathrm{mD})$ & Porosity, $\Phi$ (fraction) \\
\hline 1 & 113 & Dolomite & 2.83 & 46 & 0.174 \\
& 114 & Dolomite & 2.81 & 21 & 0.195 \\
2 & 9 & Calcite & 2.70 & 11 & 0.279 \\
& 15 & Calcite & 2.70 & 1.75 & 0.236 \\
3 & 22 & Calcite & 2.70 & 2.08 & 0.212 \\
& 72 & Calcite & 2.70 & 2.06 & 0.214 \\
& 4 & Calcite & 2.70 & 5.34 & 0.227 \\
5 & 6 & Calcite & 2.71 & 3.02 & 0.213 \\
& 138 & Calcite & 2.73 & 0.98 & 0.184 \\
\end{tabular}

Table 5 End point parameters of permeability and saturation for sample plugs

\begin{tabular}{|c|c|c|c|c|c|c|c|}
\hline Sample plug & $S_{\mathrm{wi}}$ & $S_{\mathrm{oi}}$ & $S_{\mathrm{wc}}$ & $S_{\mathrm{oi}}^{\max }$ & $S_{\mathrm{or}}^{\max }$ & $K_{\text {ro }}\left(S_{\mathrm{oi}}\right)$ & $K_{\mathrm{rw}}\left(S_{\mathrm{or}}^{\max }\right)$ \\
\hline 113 & 0.175 & 0.825 & 0.1 & 0.95 & 0.25 & 0.455 & 0.17 \\
\hline 114 & 0.2 & 0.8 & 0.14 & 0.85 & 0.35 & 0.625 & 0.17 \\
\hline 9 & 0.15 & 0.85 & 0.1 & 0.95 & 0.25 & 0.45 & 0.2 \\
\hline 15 & 0.2 & 0.8 & 0.12 & 0.95 & 0.22 & 0.46 & 0.06 \\
\hline 22 & 0.35 & 0.65 & 0.25 & 0.8 & 0.26 & 0.42 & 0.01 \\
\hline 72 & 0.3 & 0.7 & 0.2 & 0.85 & 0.2 & 0.545 & 0.08 \\
\hline 4 & 0.35 & 0.65 & 0.3 & 0.72 & 0.35 & 0.46 & 0.06 \\
\hline 6 & 0.26 & 0.74 & 0.2 & 0.85 & 0.25 & 0.44 & 0.17 \\
\hline 138 & 0.18 & 0.82 & 0.1 & 0.95 & 0.3 & 0.55 & 0.02 \\
\hline 139 & 0.2 & 0.8 & 0.1 & 0.95 & 0.3 & 0.56 & 0.02 \\
\hline
\end{tabular}

Table 6 Fitting parameters of $K_{\mathrm{r}}$ correlation for sample plugs

\begin{tabular}{|c|c|c|c|c|c|c|}
\hline Sample plug & $n_{\mathrm{wd}}$ & $n_{\mathrm{od}}\left(S_{\mathrm{oi}}\right)$ & $c_{\mathrm{d}}\left(S_{\mathrm{oi}}\right)$ & $n_{\mathrm{wi}}$ & $n_{\mathrm{oi}}\left(S_{\mathrm{oi}}\right)$ & $c_{\mathrm{i}}\left(S_{\mathrm{oi}}\right)$ \\
\hline 113 & 5.814 & 2.359 & 0.005 & 2.305 & 2.102 & -0.062 \\
\hline 114 & 3.929 & 2.319 & 0.002 & 2.145 & 4.418 & -0.041 \\
\hline 9 & 3.637 & 1.803 & 0.005 & 3.052 & 3.038 & -0.012 \\
\hline 15 & 2.441 & 2.472 & 0.005 & 14.88 & 2.610 & 0.005 \\
\hline 22 & 3.976 & 2.718 & 0.005 & 2.655 & 3.227 & 0.010 \\
\hline 72 & 2.913 & 3.067 & 0.001 & 1.715 & 3.616 & 0.005 \\
\hline 4 & 3.720 & 1.425 & 0.005 & 1.941 & 1.926 & -0.073 \\
\hline 6 & 3.684 & 1.882 & 0.005 & 2.491 & 2.608 & -0.018 \\
\hline 138 & 3.990 & 2.103 & 0.005 & 5.484 & 2.625 & 0.003 \\
\hline 139 & 3.538 & 1.950 & 0.005 & 14.75 & 2.289 & -0.063 \\
\hline
\end{tabular}

$$
\begin{aligned}
k_{\mathrm{ro}}= & k_{\mathrm{ro}}\left(S_{\mathrm{oi}}\right) \\
& \times\left[\frac{S_{\mathrm{o}}-S_{\mathrm{or}}\left(S_{\mathrm{oi}}\right)}{S_{\mathrm{oi}}-S_{\mathrm{or}}\left(S_{\mathrm{oi}}\right)}\right]^{n_{\mathrm{oi}}\left(S_{\mathrm{oi}}\right)}+\frac{c\left(S_{\mathrm{oi}}\right)}{1+c\left(S_{\mathrm{oi}}\right)}\left[\frac{S_{\mathrm{o}}-S_{\mathrm{or}}\left(S_{\mathrm{oi}}\right)}{S_{\mathrm{oi}}-S_{\mathrm{or}}\left(S_{\mathrm{oi}}\right)}\right]
\end{aligned}
$$

where $S_{\text {or }}\left(S_{\mathrm{oi}}\right), k_{\mathrm{ro}}\left(S_{\mathrm{oi}}\right)$ and $n_{\mathrm{oi}}\left(S_{\mathrm{oi}}\right)$ are the residual oil saturation, the endpoint relative permeability and the Corey exponent, and $c\left(S_{\mathrm{oi}}\right)$ is a fitting parameter to adjust the oil relative permeability to match the experimental values. The constraint for $c\left(S_{\mathrm{oi}}\right)$ shows its maximum value $0.005 . S_{\text {or }}$ 
$\left(S_{\mathrm{oi}}\right)$ is determined by a linear correlation as shown in the following Eq. 3:

$S_{\text {or }}\left(S_{\text {oi }}\right)=\frac{S_{\text {oi }} \times S_{\text {or }}^{\max }}{S_{\text {oi }}^{\max }}$

where $S_{\mathrm{or}}^{\max }$ is the maximum residual oil saturation and $S_{\mathrm{oi}}^{\max }$ is the maximum initial oil saturation.

The water relative permeabilities for drainage and imbibition are expressed by Eqs. 4 and 5, respectively, as follows:

$k_{\mathrm{rw}}^{d}\left(S_{\mathrm{w}}\right)=\left(\frac{S_{\mathrm{w}}-S_{\mathrm{wc}}}{1-S_{\mathrm{wc}}}\right)^{n_{\mathrm{wd}}}$

$k_{\mathrm{rw}}^{\mathrm{imb}}\left(S_{\mathrm{w}}\right)=k_{\mathrm{rw}}\left[S_{\mathrm{or}}\left(S_{\mathrm{oi}}\right)\right] \times\left[\frac{S_{\mathrm{w}}-S_{\mathrm{wx}}}{1-S_{\mathrm{wx}}-S_{\mathrm{or}}\left(S_{\mathrm{oi}}\right)}\right]^{n_{\mathrm{wi}}}$

where $k_{\mathrm{rw}}\left[S_{\mathrm{or}}\left(S_{\mathrm{oi}}\right)\right]$ is the water relative permeability at $S_{\mathrm{or}}\left(S_{\mathrm{oi}}\right)$, and it is given by the following Eq. 6 .

$k_{\mathrm{rW}}\left[S_{\mathrm{or}}\left(S_{\mathrm{oi}}\right)\right]=1-S_{\text {or }}\left(S_{\mathrm{oi}}\right) \times\left[\frac{1-k_{\mathrm{rw}}\left(S_{\mathrm{or}}^{\max }\right)}{S_{\text {or }}^{\max }}\right]$

On the other hand, $S_{\mathrm{wx}}$ is obtained by Eq. 7 .

$$
S_{\mathrm{wx}}=\frac{S_{\mathrm{wi}}-\left[1-S_{\mathrm{or}}\left(S_{\mathrm{oi}}\right)\right] \times\left\{\frac{k_{\mathrm{rW}}^{d}\left(S_{\mathrm{wi}}\right)}{k_{\mathrm{rw}}\left[S_{\mathrm{or}}\left(S_{\mathrm{oi}}\right)\right]}\right\}^{\left(\frac{1}{n_{\mathrm{wi}}}\right)}}{1-\left\{\frac{k_{\mathrm{rv}}^{d}\left(S_{\mathrm{wi}}\right)}{k_{\mathrm{rw}}\left[S_{\mathrm{or}}\left(S_{\mathrm{oi}}\right)\right]}\right\}^{\left(\frac{1}{n_{\mathrm{wi}}}\right)}}
$$

The characterization and experimental data of relative permeability and rock typing are sourced from the work done by Dernaika et al. (2013). According to Dernaika et al. (2013), the rock types were identified based on the whole core and plug X-ray computed tomography (CT), nuclear magnetic resonance (NMR) T2 distribution, mercury injection capillary pressure (MICP), pore-throatsize distribution, porosity and permeability that are reflected by petrophysical properties. Again thin section study provides the geological descriptions specifying pore systems, facies and depositional environment of all different rock types. After the rock typing of all samples, 10 plugs ( 2 plugs from each rock type) were selected for analysis and other measurements of SCAL properties.

The procedure of relative permeability measurement by steady state equilibrium fractional flow technique was discussed in the work of Dernaika et al. (2013) as shown in Fig. 9. A comprehensive description of the relative permeability measurement procedure is provided here. The technique is briefly discussed here for providing an overview of the method. Initially all rock samples were cleaned by flow-through techniques using several hot solvents treatment with repeated cycles to render the rock wettability condition before oil entered into the reservoir. All the core samples were then saturated with $100 \%$ synthesized formation brine of similar composition of reservoir formation water. At this time, water permeability (base permeability) was calculated by using simply Darcy's law by measuring flow rate and pressure drop. After that live fluid (oil) was injected into the core horizontally to measure the oil permeability at measured water saturation. Gamma ray as in situ saturation monitoring (gamma attenuation saturation monitoring) was used to determine the primary drainage and imbibition water and oil relative permeability by measuring effective permeabilities of water and oil by steady state equilibrium fractional flow techniques at reservoir conditions. In each primary drainage and imbibition flood, mutually equilibrated synthesized formation brine and live oil were injected concurrently into the top of every core sample and it was continued until constant pressure, brine and oil saturations and production before altering the fractional flow rate to the next predetermined step. After reaching at constant saturations of water, oil and pressure, the pressure drop, flow rates of oil and water were measured to calculate the relative permeability by using calculated effective permeability and base permeability. After changing the fractional flow rate, the system again ran until stable pressure and saturation were achieved. The stabilization criteria have no changes in saturation and pressure drop at each step for a few hours. This process was repeated for each determined fractional flow rate. Completion of one full flooding cycle took $2-3$ weeks.

Firstly, relative permeability correlation is conducted for each sample plug; afterward, it is done for RRTs. The petrophysical properties of the mineral, grain density, permeability and porosity are given in Table 4 for each sample plug and classified RRTs. For producing the curves on the basis of experimental results, saturation end points parameters used in this model are given in Table 5 for rock samples, respectively. The parameters are obtained by the primary drainage and equations included in the model. By implementing Masalmeh model, curve fitting was conducted in MATLAB to find out the best fitting parameters with matching experimental values of oil and water relative permeability for the imbibition and drainage, respectively. The results of curve fitting are shown in Table 6 .

The relative permeability correlation has been tested by Masalmeh model on a consistent set of relative permeability measurements of the rock samples taken from the mixed-wet transition zone of a well of Abu Dhabi carbonate reservoir. The drainage and imbibition of oil and water relative permeability were obtained by curve fitting against experimental results, as it is shown in Figs. 10, 11, $12,13,14,15,16,17,18$ and 19. By observing the correlation of oil and water relative permeability for drainage and imbibition, it has been found that the matches between model and experimental results are excellent. And it can be stated that Masalmeh model is applicable for generating 
Drainage 113

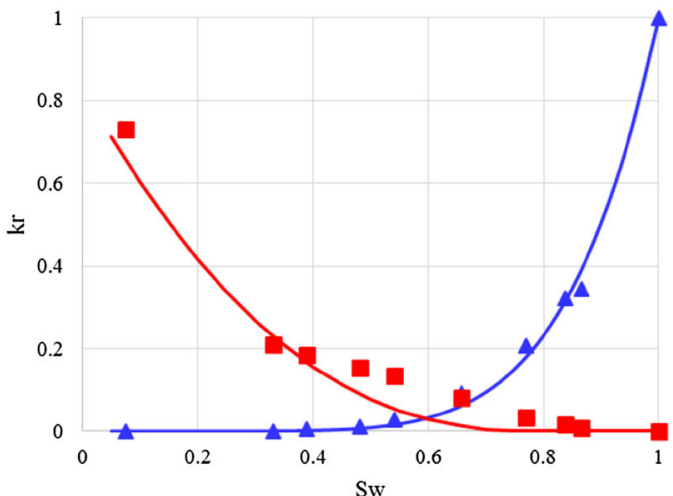

Imbibition 113

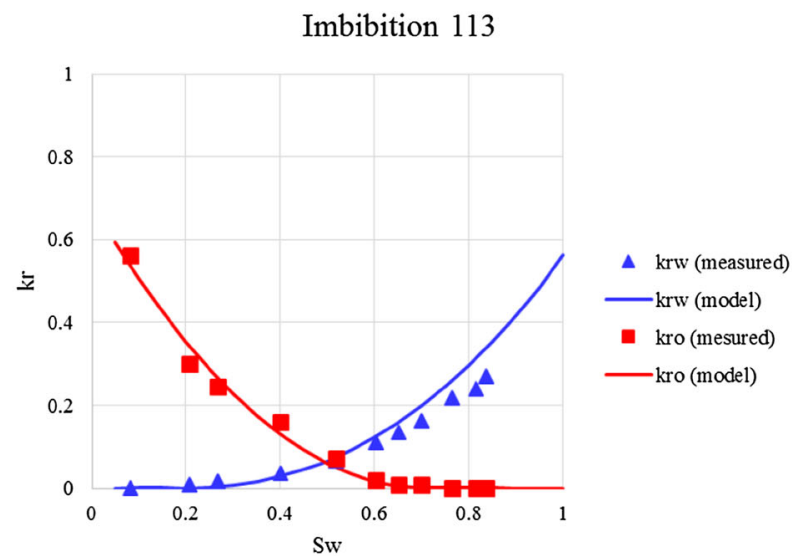

Fig. 10 Drainage and imbibition $K_{\mathrm{r}}$ correlation for sample plug \#113

\section{Drainage 114}

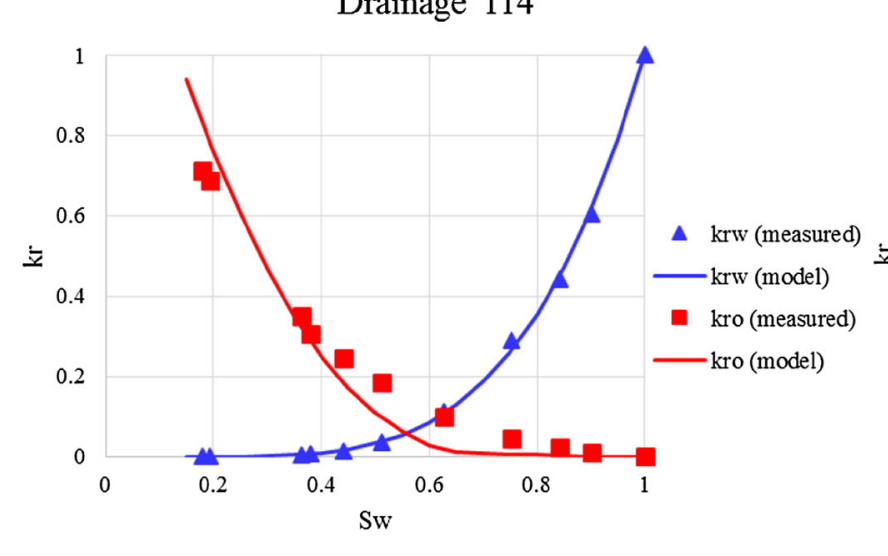

Fig. 11 Drainage and imbibition $K_{\mathrm{r}}$ correlation for sample plug \#114

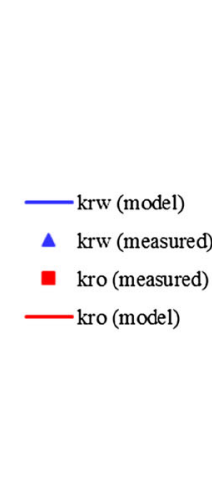

Fig. 10 Drainage and imbibition $K_{\mathrm{r}}$ correlation for sample plug \#113

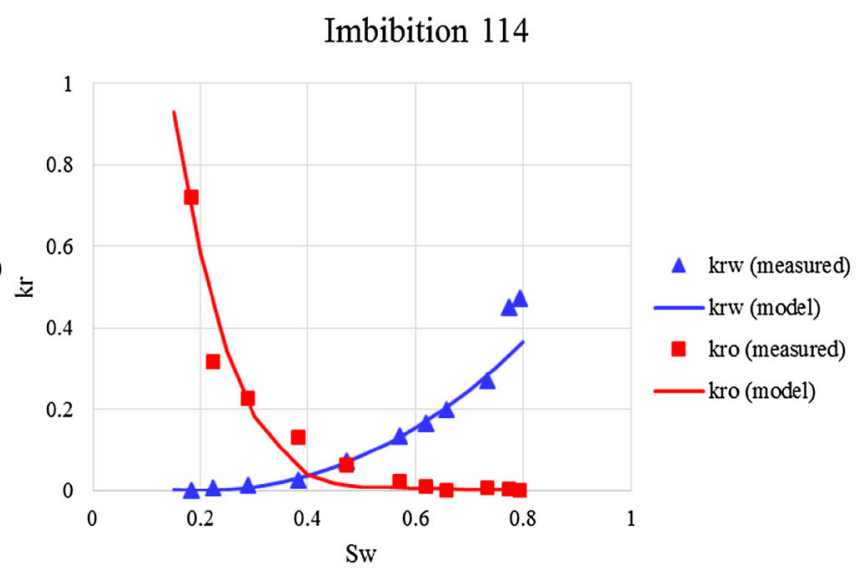

Drainage 9

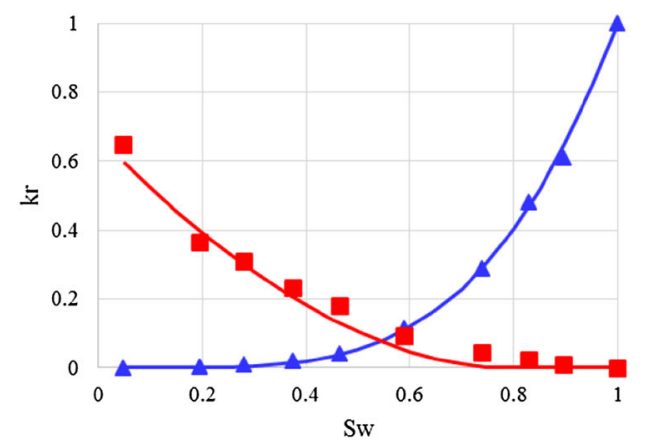

Imbibition 9

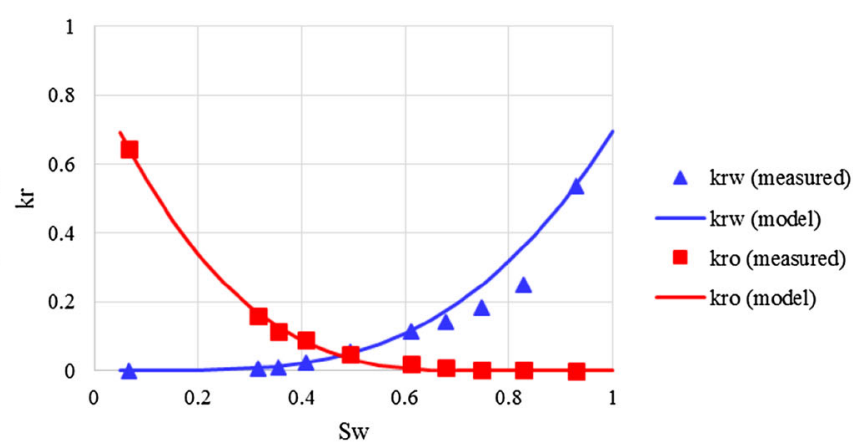

Fig. 12 Drainage and imbibition $K_{\mathrm{r}}$ correlation for sample plug \#9

representative relative permeability curves for carbonate reservoir transition zones with mixed-wet properties. This model is qualified in reservoir simulation and modeling rather than the conventional methods for water-wet reservoir only.
It has been found from Figs. 10 and 11 that there is a small difference between the primary drainage curves of the samples in the same rock types. This difference is definitely attributed due to the presence of local heterogeneity of the carbonate reservoir formation. If the poor 


\section{Drainage 15}

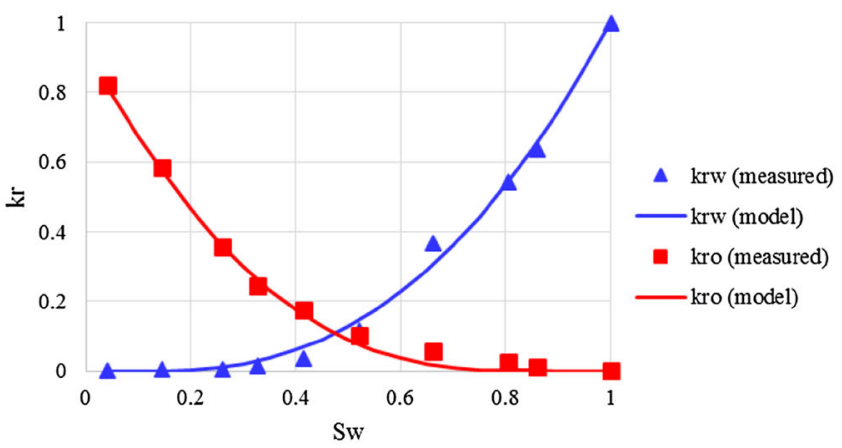

Fig. 13 Drainage and imbibition $K_{\mathrm{r}}$ correlation for sample plug \#15

\section{Drainage 22}

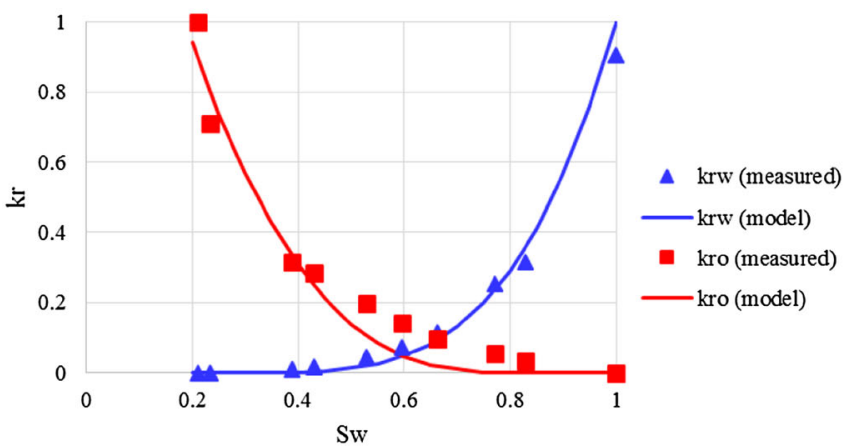

Fig. 14 Drainage and imbibition $K_{\mathrm{r}}$ correlation for sample plug \#22

\section{Drainage 72}

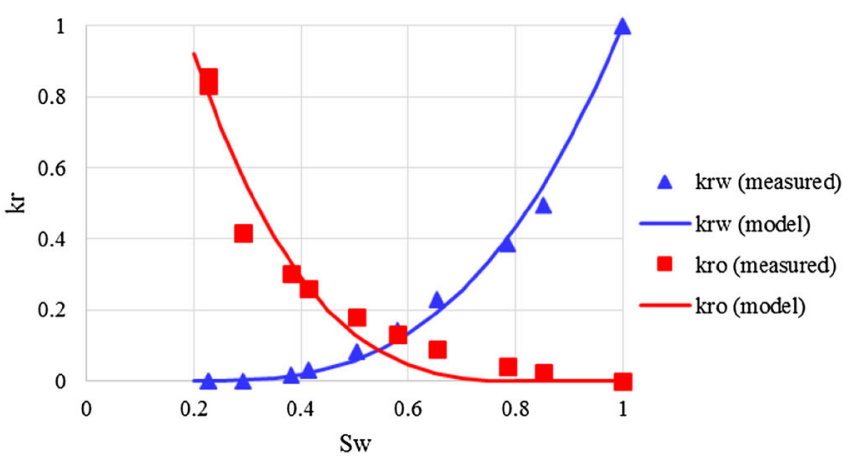

Fig. 15 Drainage and imbibition $K_{\mathrm{r}}$ correlation for sample plug \#72

rock type is considered, then the difference is supposed to be less as diversified ranges of micro- to macropores are present in the samples. For the curves, there is no direct correlation between relative permeabilities of water and oil intersection point on the saturation axis for the samples of different rock types. It has been found that the intersection points for all samples are in the range of a water saturation of $0.55-0.65$. It has also been found from Fig. 19 that relative permeability of drainage curve for oil gets flattened shape at lower water saturation indicating
Imbibition 15

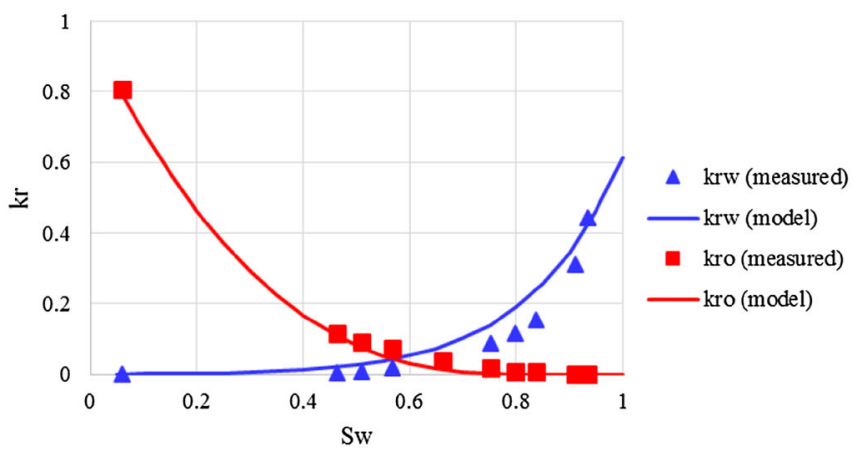

Imbibition 22

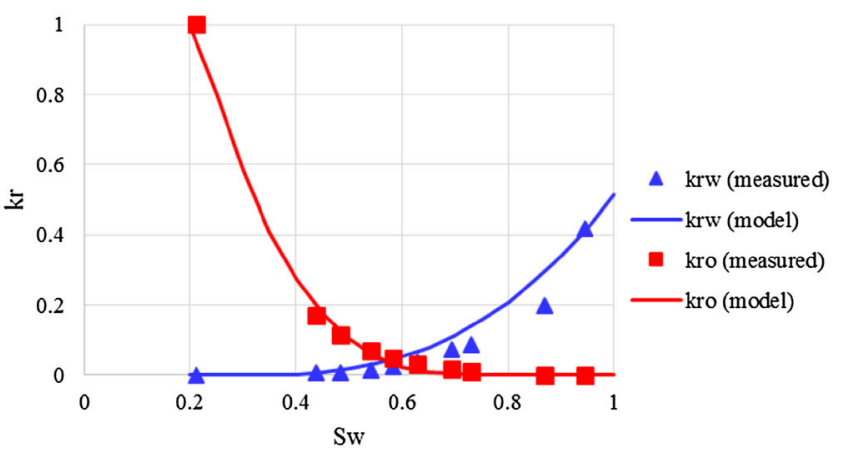

Imbibition 72

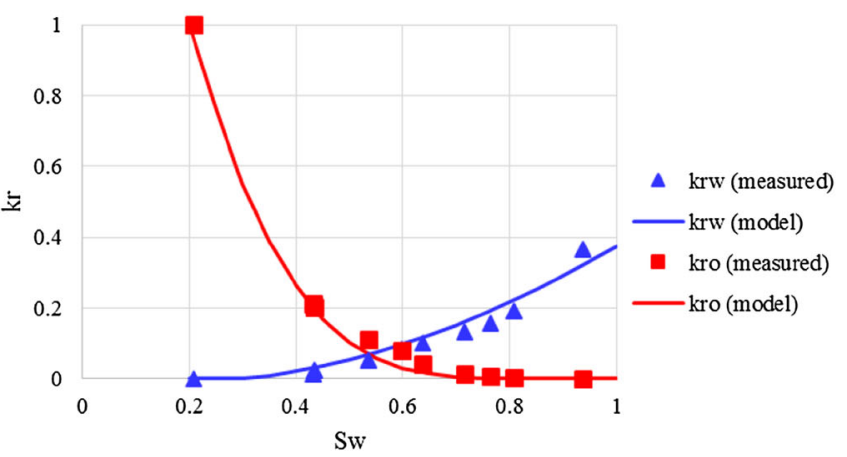

the large capillary end effect. The capillary end effect is a vital issue and has a significant influence on the computation of end point relative permeabilities and final saturation levels in core flood experiments. Capillary end effects arise from the discontinuity of capillarity in the wetting phase at the outlet end of the core sample of laboratory experiments. If the capillary pressure curve is well known before, then corrections for relative permeability and saturation can be quantified based on the curve. Different rock type samples which are water wet in nature 


\section{Drainage 4}

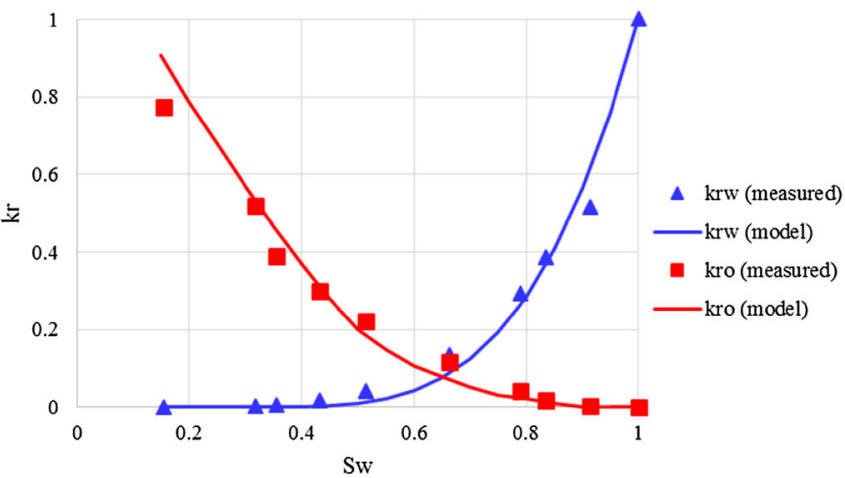

Fig. 16 Drainage and imbibition $K_{\mathrm{r}}$ correlation for sample plug \#4

\section{Drainage 6}

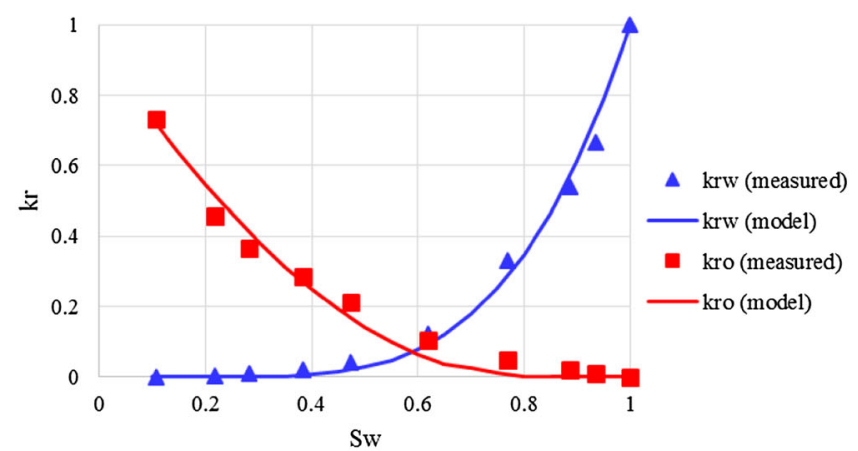

Fig. 17 Drainage and imbibition $K_{\mathrm{r}}$ correlation for sample plug \#6

\section{Drainage 138}

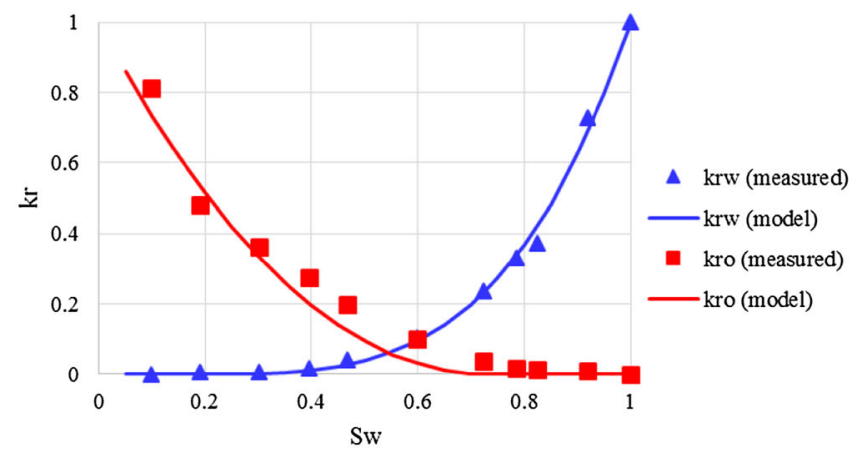

Fig. 18 Drainage and imbibition $K_{\mathrm{r}}$ correlation for sample plug \#138

may suffer different levels of capillary end effects due to dissimilarity in rock properties.

Figures $10,11,12,13,14,15,16,17,18$ and 19 also show the imbibition relative permeability curves for all rock types. It has been found that the crossover points for all samples are obtained at lower water saturation values
Imbibition 4

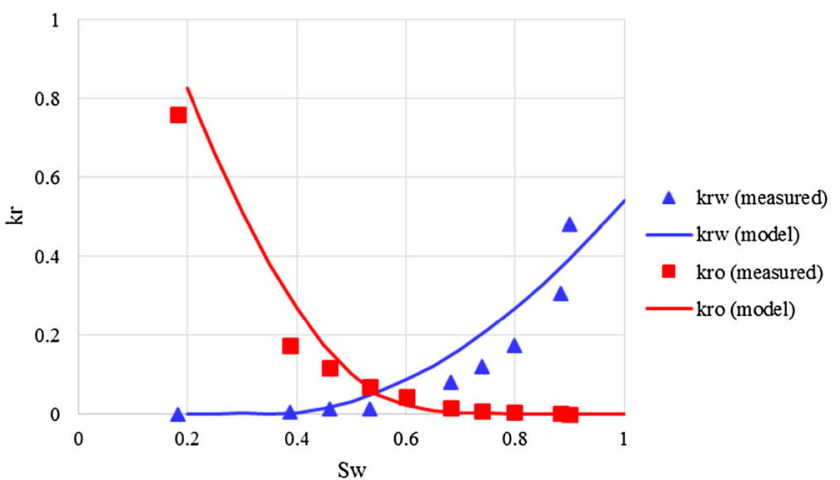

Imbibtion 6

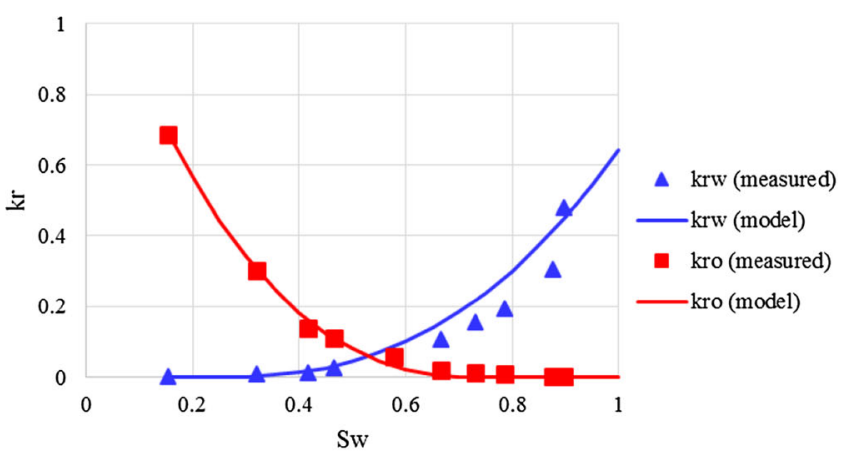

Imbibition 138

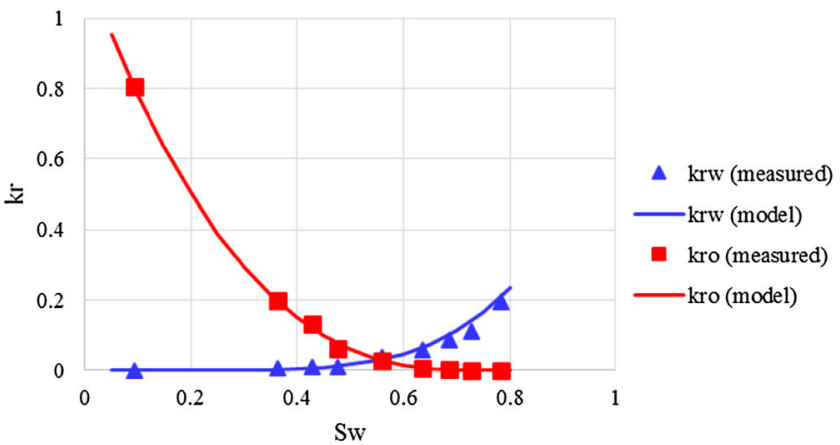

than the drainage curves. For imbibition curves, the crossover points have been found to be in the range of $0.445-0.60$ that can provide a qualitative idea about the wettability change of rock samples. It is also important to mention that each sample from same rock type shows almost similar behavior in imbibition due to local 
Drainage 139

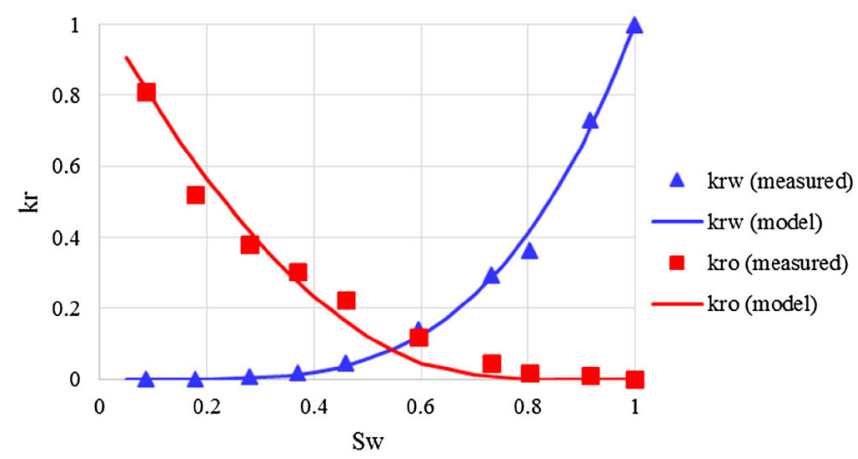

Imbibition 139

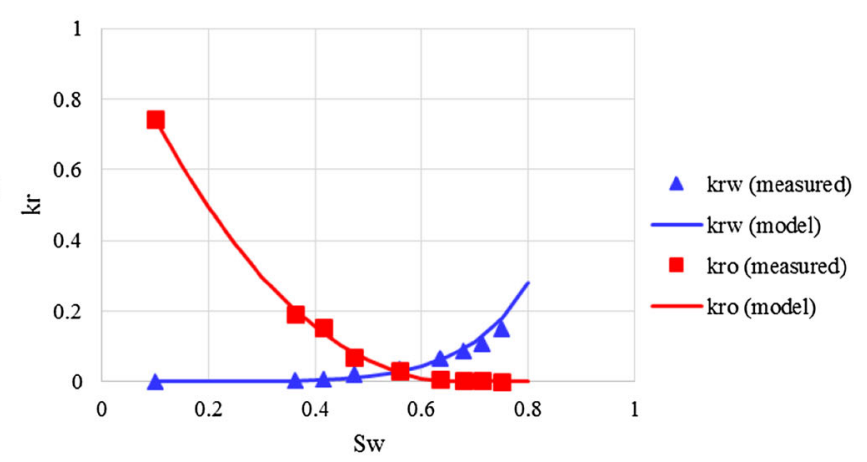

Fig. 19 Drainage and imbibition $K_{\mathrm{r}}$ correlation for sample plug \#139

Table 7 End point parameters of permeability and saturation for RRTs

\begin{tabular}{llllllll}
\hline RRT & $S_{\mathrm{wi}}$ & $S_{\mathrm{oi}}$ & $S_{\mathrm{wc}}$ & $S_{\mathrm{oi}}^{\max }$ & $S_{\mathrm{or}}^{\max }$ & $K_{\mathrm{ro}}\left(S_{\mathrm{oi}}\right)$ & 0.53 \\
\hline 1 & 0.188 & 0.812 & 0.1 & 0.9 & 0.3 & 0.24 & 0.455 \\
2 & 0.175 & 0.825 & 0.1 & 0.95 & 0.9 & 0.7 & 0.1 \\
3 & 0.25 & 0.75 & 0.2 & 0.9 & 0.26 & 0.45 & 0.02 \\
4 & 0.305 & 0.695 & 0.2 & 0.85 & 0.3 & 0.555 \\
5 & 0.19 & 0.81 & 0.1 & 0.95 & 0.3 & 0.02 \\
\hline
\end{tabular}

Table 8 Fitting parameters of $K_{\mathrm{r}}$ correlation for RRTs

\begin{tabular}{|c|c|c|c|c|c|c|}
\hline RRT & $n_{\mathrm{wd}}$ & $n_{\mathrm{od}}\left(S_{\mathrm{oi}}\right)$ & $c_{\mathrm{d}}\left(S_{\mathrm{oi}}\right)$ & $n_{\mathrm{wi}}$ & $n_{\mathrm{oi}}\left(S_{\mathrm{oi}}\right)$ & $c_{\mathrm{i}}\left(S_{\mathrm{oi}}\right)$ \\
\hline 1 & 4.913 & 1.869 & 0.005 & 2.091 & 1.997 & -0.091 \\
\hline 2 & 3.020 & 2.207 & 0.005 & 4.705 & 2.900 & 0.001 \\
\hline 3 & 3.539 & 2.726 & 0.005 & 3.045 & 3.278 & 0.005 \\
\hline 4 & 4.037 & 1.624 & 0.005 & 2.973 & 2.312 & 0.075 \\
\hline 5 & 3.810 & 2.044 & 0.005 & 6.684 & 2.449 & -0.031 \\
\hline
\end{tabular}

heterogeneity. Therefore, it can be stated that the static rock typing based on petrophysical measurements and geological study is effective as the samples from the same rock type show similar behaviors.

\section{Relative permeability $\left(K_{\mathbf{r}}\right)$ correlations for RRTs}

The relative permeability correlation was also studied for different RRTs. The end point parameters used for correlation are given in Table 7 for 5 RRTs, and the fitting parameters, shown in Table 8 , were obtained by curve fitting using Masalmeh model for drainage and imbibition of oil and water relative permeability. Figures 20, 21, 22, 23 and 24 show the relative permeability correlation curves for drainage and imbibition processes for different RRTs. It has been found from Figs. 20, 21, 22, 23 and 24 that there is no large difference among the drainage curves. It seems that the drainage curves are same although the samples from different rock types have different values of initial water saturation. At high water saturation end, the relative permeability curves for good rock type samples with large pore size become larger at the start of oil invasion. All the curves in drainage show capillary end effect at the lower water saturation end. The imbibition curves in Figs. 20, 21, 22, 23 and 24 show difference for samples of different rock types. Large pore size rock samples of rock types 1 and 2 higher relative permeability of water than the rock types 3 , 4 and 5. Therefore, it can be stated that the samples of good rock types 1 and 2 tend to more oil wet than samples of rock types 3, 4 and 5. The imbibition curves of oil also show the similar trend of the oil-wet states of rock types 1 and 2. Therefore, good rock type may also be oil wet based on the wettability condition.

It is clear from Figs. 20, 21, 22, 23 and 24 that the experimental and simulated results are well matched in 

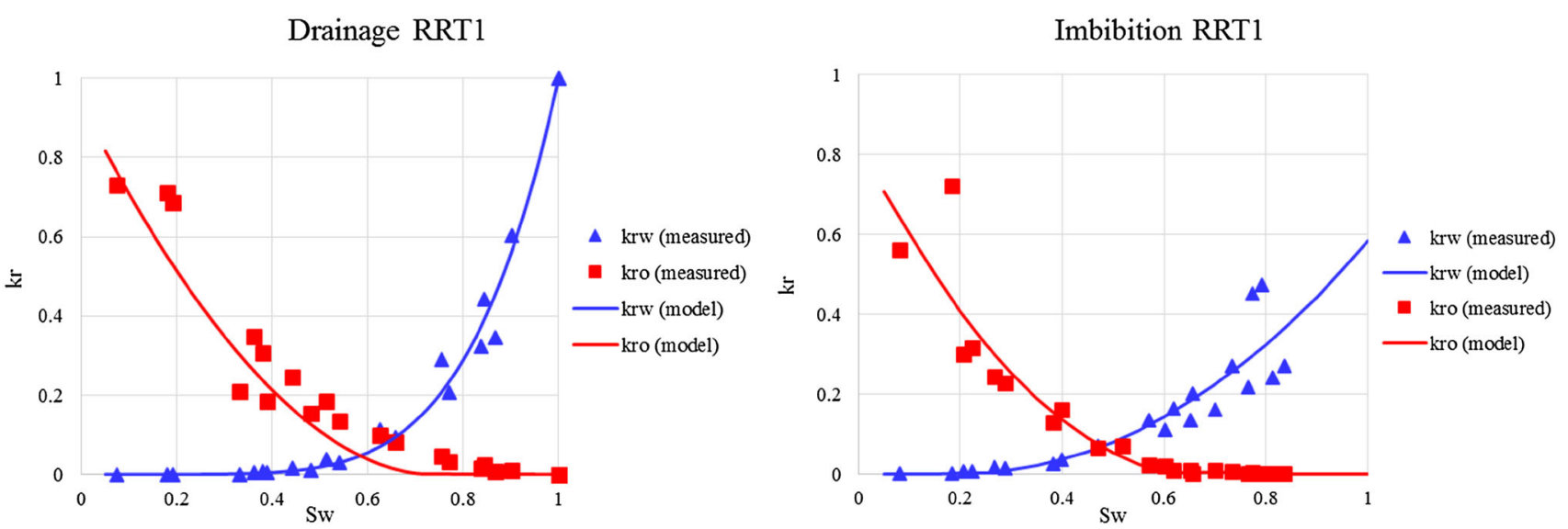

Fig. 20 Drainage and imbibition $K_{\mathrm{r}}$ correlation for RRT 1

\section{Drainage RRT2}

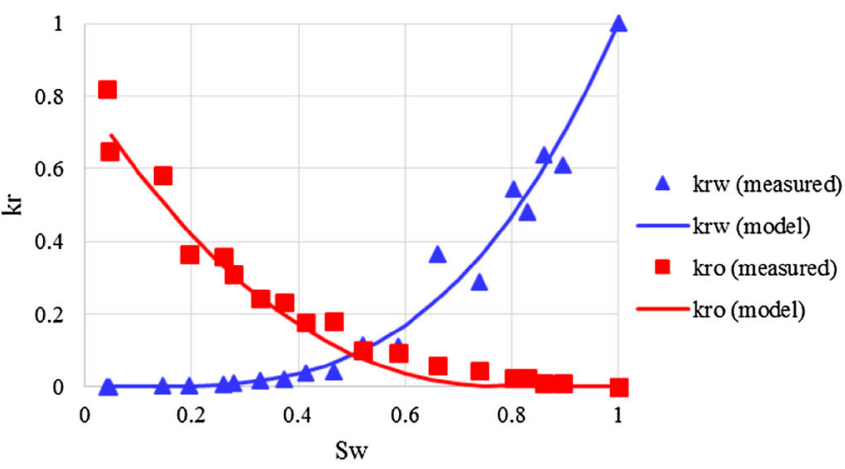

Fig. 21 Drainage and imbibition $K_{\mathrm{r}}$ correlation for RRT 2

curve fitting tool. Therefore, it can be stated that the current approach is also able to produce a good correlation of relative permeability for different RRTs of capillary transition zones of carbonate reservoirs.

\section{Relative permeability correlation for another carbonate reservoir}

To extend the applicability of the correlation model, relative permeability correlation has been applied on another filed with SCAL data. The correlation has been tested for another two samples of Abu Dhabi carbonate reservoirs. The detailed properties of the core samples are given in Table 9. The end point parameters and fitting parameters of relative permeability have been shown in Tables 10 and 11 , respectively. On the other hand Figs. 25 and 26 show the drainage and imbibition relative permeability correlation graphs. It is confirmed that the model produced curves are well matched with experimental results. It has also been found from the results in Table 9 that irreducible water saturation (Swirr) values for samples $2 \mathrm{H}$ and $6 \mathrm{H}$ reached approximately to 21 and $35 \%$ in drainage process, respectively. The increase in Swirr causes due to change in wettability from oil-wet to water-wet behavior with variation of depth.

\section{Conclusions}

Capillary pressure and relative permeability correlations for understanding the dynamic behaviors of transition zones in carbonate reservoirs are utmost important in reservoir characterization and modeling. Several models are available to predict the capillary pressure and relative permeability behaviors of transition zones in carbonate reservoirs. It is important to choose the best model which can properly predict the transition zone fluid behavior for different types of wettability of the rocks. Based on the present study, the followings conclusions can be made:

1. Skjaeveland model can be applied for capillary pressure correlation for both imbibition and secondary 
Drainage RRT3

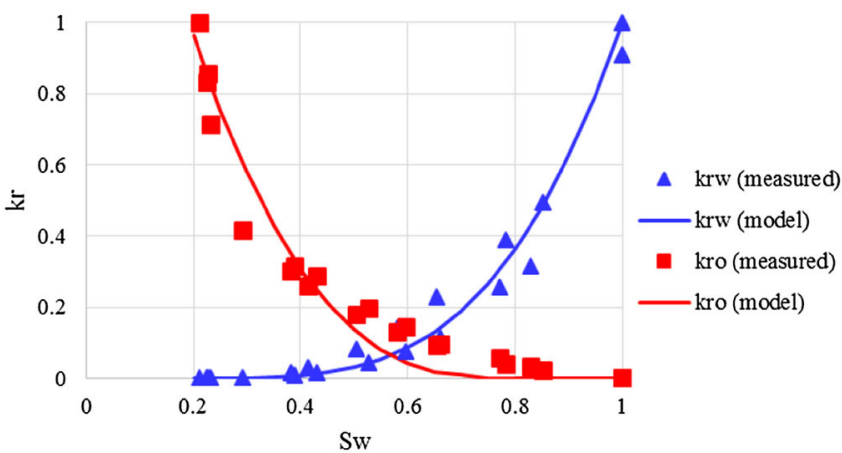

Fig. 22 Drainage and imbibition $K_{\mathrm{r}}$ correlation for RRT 3

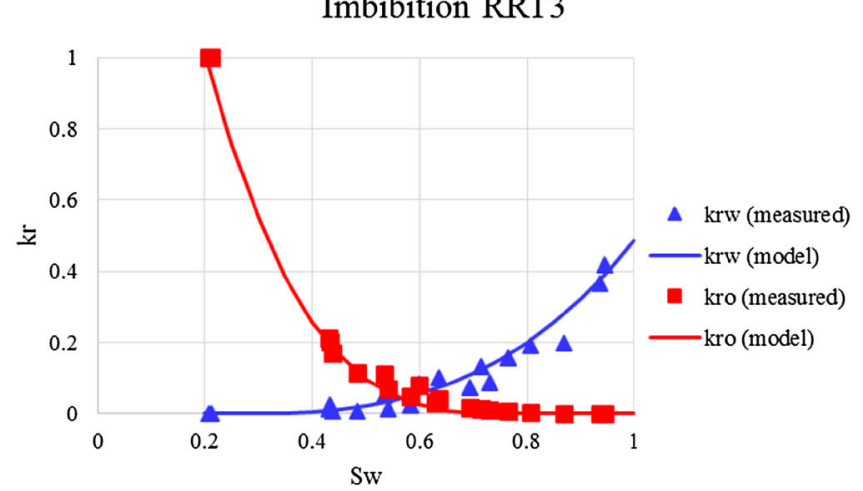

Imbibition RRT3
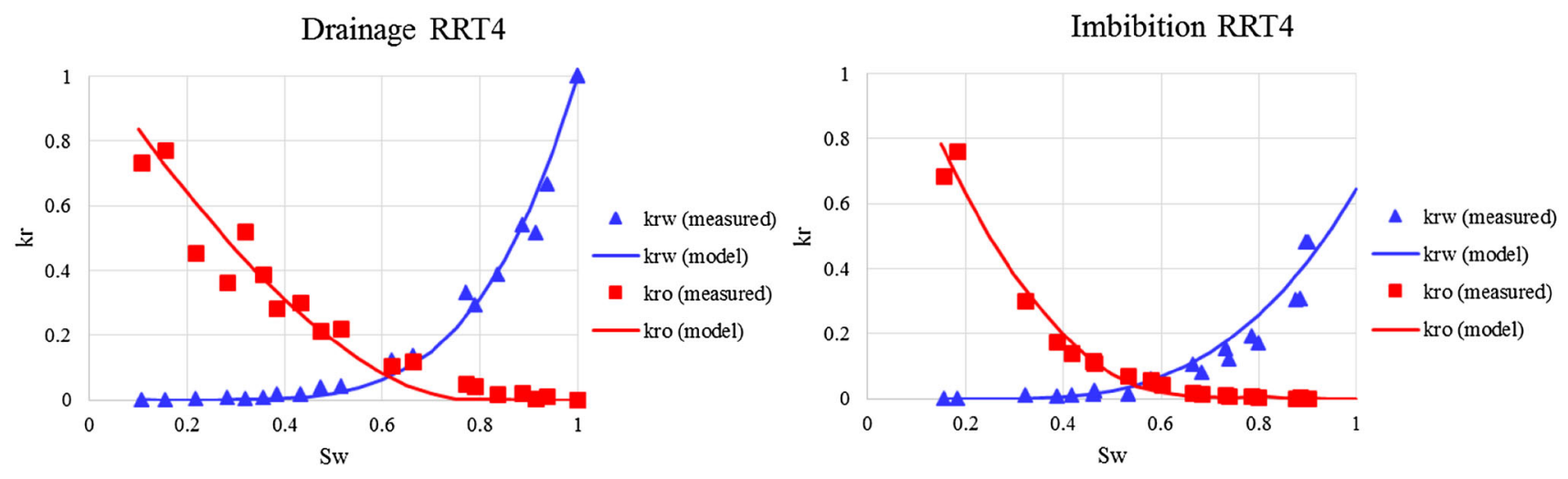

Fig. 23 Drainage and imbibition $K_{\mathrm{r}}$ correlation for RRT 4

Drainage RRT5

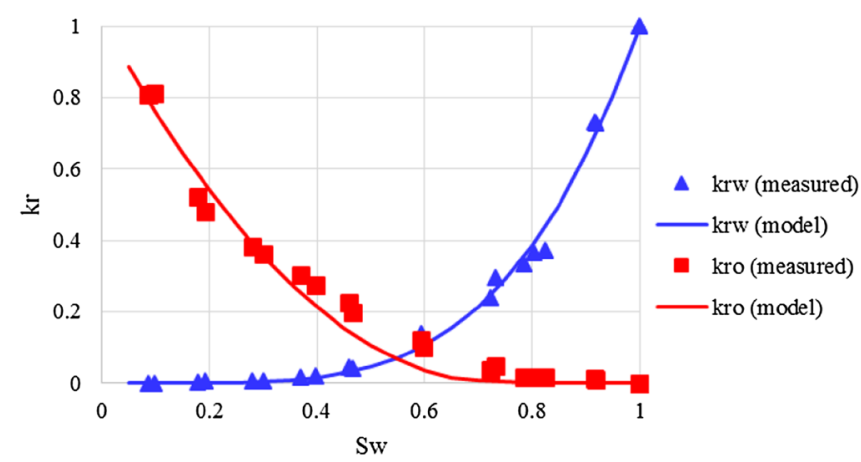

Imbibition RRT5

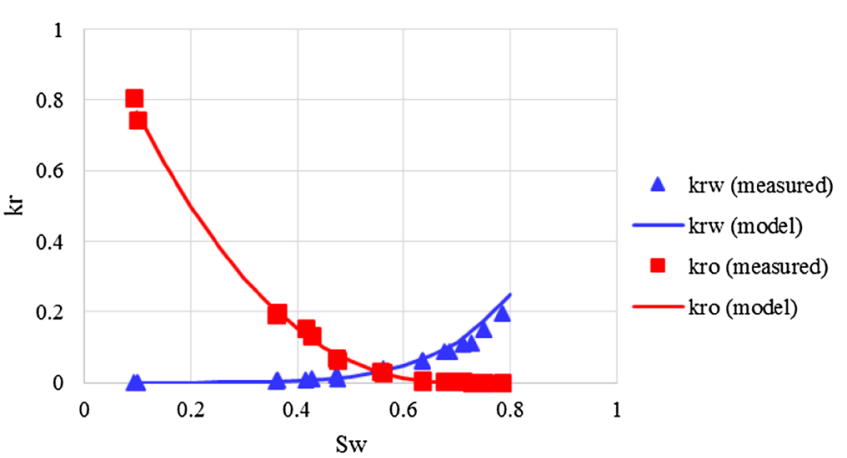

Fig. 24 Drainage and imbibition $K_{\mathrm{r}}$ correlation for RRT 5

Table 9 Summary of core plug samples characterization

\begin{tabular}{llllll}
\hline Sample plug & Depth (ft) & RRT & GD $(\mathrm{g} / \mathrm{cc})$ & $k(\mathrm{mD})$ & $\Phi(\%)$ \\
\hline SN14-2H & 9512.17 & 1 & 2.67 & 7.2 & $S_{\text {wc }}$ \\
SN14-6H & 9544.88 & 2 & 2.68 & 5.5 & 13.8 \\
\hline
\end{tabular}


Table 10 End point parameters of permeability and saturation for the core samples

\begin{tabular}{llllllll}
\hline Sample plug & $S_{\mathrm{wi}}$ & $S_{\mathrm{oi}}$ & $S_{\mathrm{wc}}$ & $S_{\text {oi }}^{\max }$ & $S_{\text {or }}^{\max }$ & $K_{\text {ro }}\left(S_{\text {oi }}\right)$ & 0.7 \\
\hline SN14-2H & 0.225 & 0.775 & 0.21 & 0.9 & 0.33 & 0.17 \\
SN14-6H & 0.3776 & 0.6224 & 0.352 & 0.75 & 0.3 & 0.41 & 0.02 \\
\hline
\end{tabular}

Table 11 Fitting parameters of $K_{\mathrm{r}}$ correlation for core samples

\begin{tabular}{lllllll}
\hline Sample plug & $n_{\mathrm{wd}}$ & $n_{\mathrm{od}}\left(S_{\mathrm{oi}}\right)$ & $c_{\mathrm{d}}\left(S_{\mathrm{oi}}\right)$ & $n_{\mathrm{wi}}$ & $n_{\mathrm{oi}}\left(S_{\mathrm{oi}}\right)$ & 4.894 \\
\hline SN14-2H & 2.829 & 3.641 & 0.005 & 2.445 & $c_{\mathrm{i}}\left(S_{\mathrm{oi}}\right)$ \\
SN14-6H & 2.747 & 4.762 & 0.005 & 4.663 & 3.055 & 0.00218 \\
\hline
\end{tabular}

Drainage kr SN14-2H

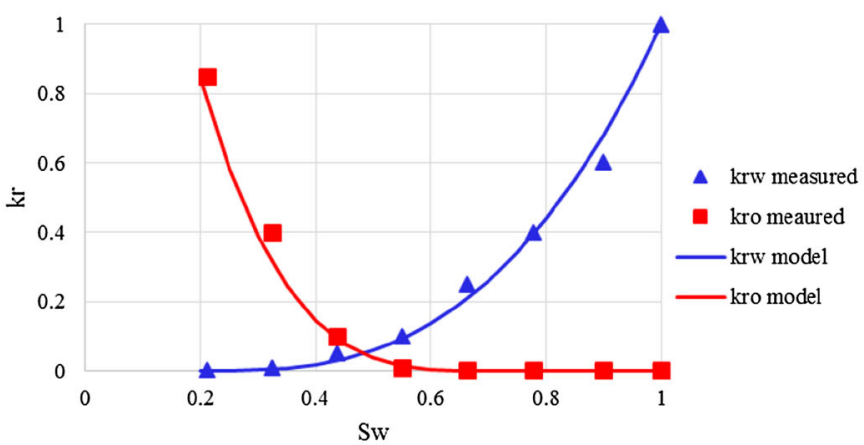

Fig. 25 Drainage and imbibition $K_{\mathrm{r}}$ correlation for SN14-2H

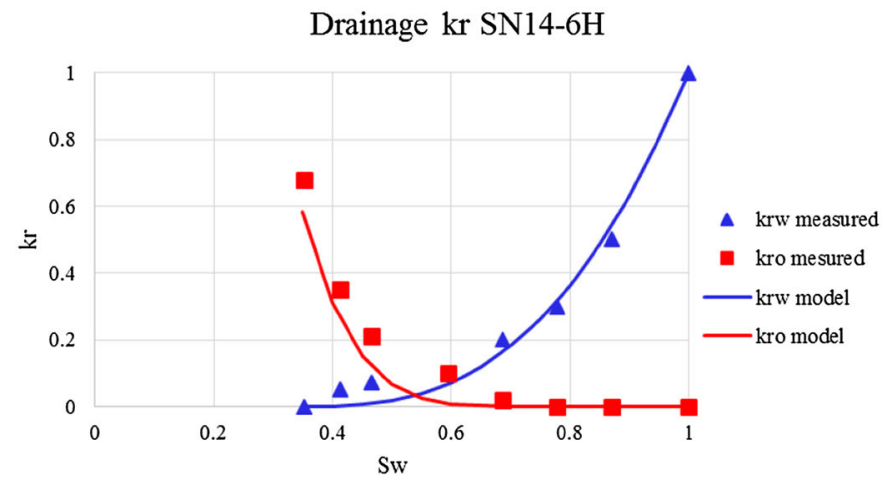

Fig. 26 Drainage and imbibition $K_{\mathrm{r}}$ correlation for SN14-6H

drainage processes of transition zones in carbonate reservoirs.

2. Results show that the model and experimental results are excellently matched with a correlation coefficient above 0.95 regardless of the wettability variation through the interval of the transition zone. Therefore, MATLAB user interface curve fitting by using Skjaeveland model can produce the proper correlation for transition zones in carbonate reservoirs.
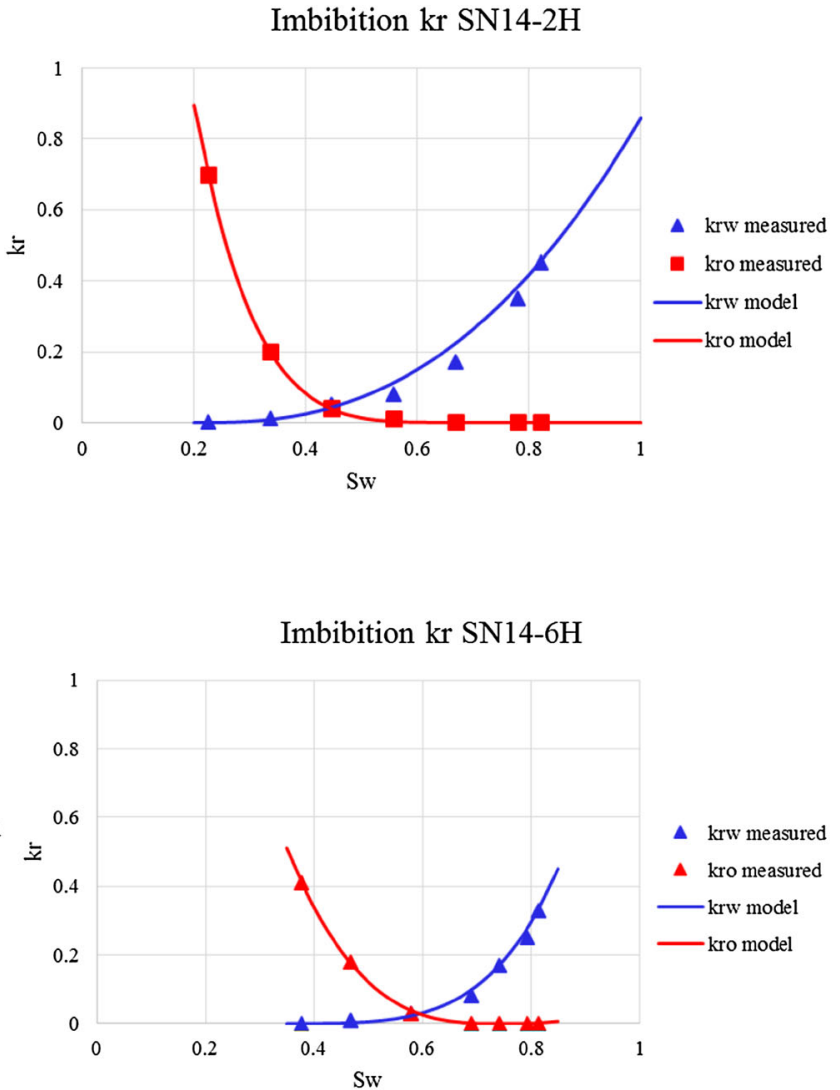

3. Based on the results, it can be concluded that Masalmeh model is applicable for generating representative relative permeability curves for carbonate reservoir transition zones with mixed-wet properties. Other models are available for relative permeability, but Masalmeh model provides proper correlation for mixed-wet transition zones of the carbonate reservoirs.

4. Relative permeability correlation based on Masalmeh model has also been applied to other core samples of a 
different field. The results show well curve fitting of experimental and simulated results.

Acknowledgements The authors would like to acknowledge the Abu Dhabi National Oil Company (ADNOC) and its Group of Subsidiary Companies including Abu Dhabi Company for Onshore Oil Operations (ADCO) and Abu Dhabi Marine Operating Company (ADMAOPCO) for supporting the work on Transition Zones in Carbonate Reservoir project (Project No. OSC13001). Special thanks to the Petroleum Institute, Abu Dhabi, for hosting this research work. The authors also thank the other individuals those who directly or indirectly associated with this project.

Open Access This article is distributed under the terms of the Creative Commons Attribution 4.0 International License (http:// creativecommons.org/licenses/by/4.0/), which permits unrestricted use, distribution, and reproduction in any medium, provided you give appropriate credit to the original author(s) and the source, provide a link to the Creative Commons license, and indicate if changes were made.

\section{References}

Bera A, Belhaj H (2016) A comprehensive review on characterization and modeling of thick capillary transition zones in carbonate reservoirs. J Unconv Oil Gas Resour 16:76-89

Brooks RH, Corey AT (1966) Properties of porous media affecting fluid flow. J Irrig Drain Div 92(2):61-90

Carlson FM (1981) Simulation of relative permeability hysteresis to the nonwetting phase. SPE annual technical conference and exhibition, 4-7 October, San Antonio, Texas. SPE-10157-MS

Clerke EA, Martin PR (2004) Thomeer Swanson excel spreadsheet and FAQs and user comments. Carbonate petrophysics workshop of SPWLA 45th annual logging symposium, 6-9 June, Noordwijk, Netherlands

Corey AT (1954) The interrelation between gas and oil relative permeabilities. Prod Mon 19(1):38-41

Dernaika MR, Basioni MA, Dawoud AM, Kalam MZ, Skjæveland SM (2013) Variations in bounding and scanning relative permeability curves with different carbonate rock type. SPE Reserv Eval Eng 16(03):265-280

Huang DD, Honarpour MM, Al-Hussainy R (1997) An improved model for relative permeability and capillary pressure incorporating wettability. Paper SCA-9718 presented at the 1997 society of core analysts international symposium, Calgary, 7-10 September 1997

Killough JE (1976) Reservoir simulation with history-dependent saturation functions. SPE J 16(01):37-48. SPE-5106-PA

Kjosavik A, Ringen JK, Skjaeveland SM (2002) Relative permeability correlation for mixed-wet reservoirs. SPE J 7(01):49-58

Land CS (1968) The optimum gas saturation for maximum oil recovery from displacement by water. Fall meeting of the society of petroleum engineers of AIME, 29 September-2 October, Houston, Texas. SPE-2216-MS

Land CS (1971) Comparison of calculated with experimental imbibition relative permeability. SPE J 11(04):419-425

Laroche C, Vizika O, Kalaydjian F (1999) Network modeling to predict the effect of wettability heterogeneities on multiphase flow. SPE annual technical conference and exhibition, 3-6 October, Houston, Texas. SPE-56674-MS

Leverett MC (1941) Capillary behavior in porous solids. Trans AIME 142(01):151-169

Masalmeh SK (2002) The effect of wettability on saturation functions and impact on carbonate reservoirs in the middle east. SPE78515-MS Abu Dhabi international petroleum exhibition and conference, 13-16 October, Abu Dhabi, United Arab Emirates

Masalmeh SK, Abu-Shiekah IM, Jing XD (2007) Improved characterization and modeling of capillary transition zones in carbonate reservoirs. SPE Reserv Eval Eng 10(02):191-204

Mohamed AAI, Belhaj H, Gomes JS, Bera A (2017) Petrographic and diagenetic studies of thick transition zone of a middle-east carbonate reservoir. Jo Pet Gas Eng 8(1):1-10

Morrow NR (1990) Wettability and its effect on oil recovery. JPT 42(12):1476-1484

Nono F, Bertin H, Hamon G (2014) An experimental investigation of the oil recovery in the transition zone of carbonate reservoirs taking into account wettability change. IPTC 17640, presented in IPTC 2014: international petroleum technology conference, Doha, Qatar, 20-22 January 2014

Skjaeveland SM, Siqveland LM, Kjosavik A, Hammervold WL, Virnovsky GA (2000) Capillary pressure correlation for mixedwet reservoirs. SPE Reserv Eval Eng 3(1):60-67

Spearing MC, Abdou M, Azagbaesuweli G, Kalam MZ (2014) Transition zone behavior: the measurement of bounding and scanning relative permeability and capillary pressure curves at reservoir conditions for a giant carbonate reservoir. Paper SPE171892-MS presented at the Abu Dhabi international petroleum exhibition and conference, Abu Dhabi, UAE, 10-13 November

Thomeer JHM (1960) Introduction of a pore geometrical factor defined by the capillary pressure curve. J Pet Technol 12(03):354-358 